\title{
Unknown Knowns: Case Studies in Uncertainties in the Computation of Thermochemical Parameters
}

\author{
J. M. Simmie* \\ School of Chemistry, National University of Ireland, Galway H91 TK33, Ireland \\ E-mail: john.simmie@nuigalway.ie \\ Phone: +353-91-492451
}

\begin{abstract}
Both the computation of, and the uncertainties associated, with gas-phase molar formation enthalpies are now quite well established for systems comprised of tens of 'heavy' atoms chosen from the commonest elements. The same cannot be said for derived thermochemical quantities such as entropy, heat capacity and an enthalpy function. Whilst the application of well known statistical thermodynamic relations is mostly understood, the determination of the uncertainty with which such values can be obtained has been little studied - apart, that is, for a general protocol devised by Goldsmith et al. [J. Phys. Chem. A, 2012, 116, 9033-9057]. Specific examples from that work are explored here and it is shown that their estimates are overly pessimistic. It is also evident that for some species the calculated thermochemical parameters show very little variation with either the level of theory, or basis set, or treatment of vibrational modes - this renders the inclusion of such species in databases designed to validate new methods of limited value.
\end{abstract}

Draft: November 23, 2020 


\section{Introduction}

There has been very few attempts to document the uncertainties in the theoretical calculation of thermochemical parameters such as entropy $\left(S^{\ominus}\right)$, isobaric heat capacity $\left(C_{p}^{\ominus}\right)$ and enthalpy functions $\left(H_{T}^{\ominus}-H_{0}^{\ominus}\right)$. Given that the experimental determination of such quantities has greatly diminished over the last decades, both because it is perceived to be unfashionable and from more practical considerations, such as health and safety concerns, this is a serious oversight. In addition highly reactive or transients such as radicals and charged species have largely proven to be less amenable to experiment - thus, computational methods have effectively become the norm.

Knowledge of these parameters is crucial to the solution of the conservation equations in reactive flows and generally in the kinetic simulation and modelling of atmospheric and combustion chemistries. $^{1-3}$

The most comprehensive effort to our knowledge was made by Goldsmith et al. who, noting that the absence of benchmark values for entropy and heat capacity is a considerable hindrance, developed a protocol to estimate the uncertainties for a large collection of species relevant to combustion chemistry. ${ }^{4}$ They assumed that the vibrational wavenumbers (frequencies) obtained at the B3LYP/6-311++G(d,p) level had upper and lower bounds of $\pm 10 \%$, that the hindered rotor potentials varied by $\pm 20 \%$ and that the external moments of inertia similarly varied by $\pm 5 \%$. Thus:

$$
\begin{aligned}
\bar{\nu}_{j} & =(0.9+0.2 x) \bar{\nu}_{j, 0} \\
V_{k}(\phi) & =(0.8+0.4 x) V_{k, 0} \\
I_{a} & =(0.95+0.1[1-x]) I_{a, 0}
\end{aligned}
$$

where $\bar{\nu}_{j}$ is one of the $\left(3 N-6-N_{h r}\right)$ modes of a species with $N>2$ atoms and $N_{h r}$ hindered vibrational modes, $V_{k}$ is the potential energy of a hindered mode and $I_{a}$ is one of the three moment of inertia. The subscript notation $z_{0}$ indicates the nominal value of a parameter $z$ 
and the variable $x$ satisfies $x \in[0,1]$. 'Low' values are given by $x=0$ and 'high' values by $x=1$.

With these assumptions they were able to derive a set of uncertainties which represented an average of the worst case scenario in which the parameters are tightly correlated. Their 219 species ranged from hydrogen to butane but included, for example, singlet and triplet states of oxoethenylidene, $\mathrm{O}=\mathrm{C}=\mathrm{C}$ : and doublets such as $\mathrm{HC}^{\bullet}\left(\mathrm{CH}_{2} \mathrm{OOH}\right)_{2}$, 2-hydroperoxy-1(hydroperoxymethyl)-ethyl. Given that the relationships that link frequencies to rotational potentials to external moments are in general unknown these were all very reasonable assumptions and indeed necessary in order to provide an estimate of the possible uncertainties.

A more limited approach was used by Cervinka et al. in analysing ${ }^{5,6}$ the uncertainties resulting from using a one-dimensional hindered rotor (HR) model for a set of 60 closed shell molecules; they found that errors of $20 \%$ in the HR contribution to the entropy and of $5 \%$ to the isobaric heat capacity was possible as a consequence of uncertainties in the potential energy barrier.

The question at issue here is: how reliable are such estimates of the uncertainty? We focus on just a few species, the afore-mentioned trans-glyoxal, a radical of formic acid anhydride, formyloxy oxomethyl, $\mathrm{HC}(\mathrm{O}) \mathrm{OC}^{\bullet} \mathrm{O}$, a radical of dimethyl carbonate, $\mathrm{H}_{3} \mathrm{COC}^{\bullet}(\mathrm{O})_{2}$, the npropylperoxy radical and finally two unsaturated alcohols in order to analyse in detail the various issues involved. It is important to step outside the closed-shell 'zoo' and include open-shell species as indeed Goldsmith and colleagues did in their pioneering work. ${ }^{4}$

The general approach to be followed here will be to use multiple model chemistries, typically four, to compute the geometries and frequencies which provide the data needed to calculate the desired thermochemistry — the expectation is that this will provide either a measure of the uncertainties or highlight inconsistencies or both. This strategy mirrors earlier work on molecules and radicals where the formation enthalpies were the primary targets. ${ }^{7-10}$

The underlying statistical thermodynamic relationships are well known ${ }^{11}$ although their 
application can be problematic - this is particularly true for certain vibrational modes. These include ring puckering ${ }^{12}$ and umbrella ${ }^{13}$ modes and coupled hindered rotors. ${ }^{14}$ None of which are insoluble per se but the effort required far exceeds the objectives of this work or indeed in the majority of publications devoted to the understanding of atmospheric and combustion chemical kinetic mechanisms - effectively contradicting Anton Chekhov's apocryphal quotation "Only entropy is easy".

\section{Computational methodology}

A number of rung four density functionals (DF) have been tested including B3LYP, ${ }^{15,16}$ BMK, ${ }^{17} \mathrm{M} 06-2 \mathrm{X},{ }^{18} \omega \mathrm{B} 97 \mathrm{X}-\mathrm{D},{ }^{19} \mathrm{MN} 12-\mathrm{L},{ }^{20} \mathrm{MN} 15^{21}$ as well as a non-empirical double hybrid PBE0-DH ${ }^{22}$ and B2PLYP. ${ }^{23}$ The selection from the over 250 known functionals ${ }^{24}$ is partially based on previous usage and convenience. All the computations were performed with Gaussian-16, ${ }^{25}$ invariably with the keywords Opt=VTight and Int=SuperFine with Freq=Anharmonic with the majority of the results at cc-pVTZ+d; visualisation with Chemcraft $^{26}$ and the results processed by the Thermo module of MultiWell ${ }^{27}$ in order to calculate thermochemical parameters without any attempt at scaling.

\section{Results}

\section{Case study I: trans-glyoxal}

The glyoxal molecule is a good choice to investigate both because it is featured in the Goldsmith work but also because the torsional potentials, that is, internal rotation about the $\mathrm{C}-\mathrm{C}$ bond, for a number of popular density functionals were recently benchmarked against CCSD(T)/aug-ccpVTZ values. ${ }^{28}$ In addition glyoxal itself is not unimportant participating in atmospheric reactions such as ozone and secondary organic aerosol formation. ${ }^{29-31}$

The Goldsmith treatment assumes that each species can be considered as a rigid-rotor 
harmonic oscillator with 1D hindered internal rotational modes as appropriate - this is common practice in practical statistical thermodynamics which typically also neglects coupling between modes. Their work thus reports $S^{\ominus}(298.15 \mathrm{~K})=270.3 \pm 3.4 \mathrm{~J} \mathrm{~K}^{-1} \mathrm{~mol}^{-1}$ and $C_{p}^{\ominus}(300 \mathrm{~K})=60.7 \pm 3.4 \mathrm{~J} \mathrm{~K}^{-1} \mathrm{~mol}^{-1}$ with frequencies obtained at the B3LYP $/ 6-311++\mathrm{G}(\mathrm{d}, \mathrm{p})$ level of theory and 1-dimensional hindered rotors at B3LYP/6-31G(d,p). The uncertainty in the isobaric heat capacity peaks at $500 \mathrm{~K}, C_{p}^{\ominus}=81.2 \pm 5.0 \mathrm{~J} \mathrm{~K}^{-1} \mathrm{~mol}^{-1}$, and decreases at $1,500 \mathrm{~K}, C_{p}^{\ominus}=118.0 \pm 0.8 \mathrm{~J} \mathrm{~K}^{-1} \mathrm{~mol}^{-1}$.

As regards torsional potentials Tahchieva et al. show that density functionals typically underestimate the trans $\rightarrow$ cis rotational barrier, vis-à-vis $\operatorname{CCSD}(\mathrm{T}) /$ aug-cc-pVTZ, with the exception of M05-2X, M06-2X and M06-HF which overestimate it, with B2PLYP performing best. ${ }^{28}$ But the consequences of such deviations from the 'gold standard' are currently unknown.

\section{Frequencies}

Geometry optimisation indicates a ${ }^{1} A_{g}$ ground state of $C_{2 h}$ symmetry; the cis-conformer lies at $+17.5 \mathrm{~kJ} \mathrm{~mol}^{-1}$. Calculated harmonic frequencies and anharmonicity coefficients for all twelve modes are all in good agreement, Table 1, where angle brackets $\langle$ and $\rangle$ denote an average and $\sigma$ is the sample standard deviation. The maximum variance of just less than $3 \%$ occurs for $\bar{\nu}_{7}$ of $a_{u}$ symmetry; although such variation in the lowest frequency would have have the strongest impact on the computed entropy - it does make up $59 \%$ of the total vibrational entropy — this mode more properly corresponds to a hindered rotor.

Athough Jacobsen et al. recommended ${ }^{32}$ anharmonic vibrational scaling factors, of 1.010 for B3LYP/cc-pVTZ frequencies below 2,500 $\mathrm{cm}^{-1}$ and unit scaling above, these are not adopted here since the nett effect is slight, for example, applying the $1 \%$ scale factor just to anharmonic B3LYP/cc-pVTZ+d frequencies but not to mode \# 7 gives rise to decreases of -0.2 and $-0.3 \mathrm{~J} \mathrm{~K}^{-1} \mathrm{~mol}^{-1}$ in the room temperature entropy and isobaric heat capacity respectively. In a similar vein Kesharwani and co-workers present 'harmonic' scale factors 
for B3LYP, M06-2X, $\omega$ B97X-D and B2PLYP of 1.0038, 0.9870, 0.9909 and 0.9983 at ccpVTZ + d, respectively. ${ }^{33}$ There is insufficient justification to apply these corrections at this time.

\section{Hindered rotor}

Relaxed potential energy scans of the $\mathrm{C}-\mathrm{C}$ bond as a function of basis set for a number of functionals shows that there is indeed little variation once past the smallest basis, Table 2, and that M06-2X does overestimate the barrier in comparison to the other functionals. There is good agreement with the reported energy barrier of $25.1 \mathrm{~kJ} \mathrm{~mol}^{-1}$ of Červinka and coworkers ${ }^{5}$ computed from a B3LYP-D3/6-311 $\mathrm{G}(2 \mathrm{df}, \mathrm{p})$ relaxed scan and the experimental ${ }^{34}$ value of $24.8 \pm 1.0 \mathrm{~kJ} \mathrm{~mol}^{-1}$. CCSD $/ 6-311++\mathrm{G}(\mathrm{d}, \mathrm{p})$ and $\mathrm{cc}-\mathrm{pVTZ}+\mathrm{d}$ scans show little difference with barriers of 26.4 and $27.5 \mathrm{~kJ} \mathrm{~mol}^{-1}$, respectively.

\section{Entropy and isobaric heat capacity}

Here we test a number of functionals, all at a common basis of cc-pVTZ $+\mathrm{d}$, and compare rigid rotor anharmonic treatments with a hindered rotor approach using relaxed potential energy scans with the same functional and basis set, Table 3. As can be seen the replacement of a vibrational mode by a hindered rotor makes little discernible difference; this is not unexpected since the cis-glyoxal conformer lies some $18 \mathrm{~kJ} \mathrm{~mol}^{-1}$ above the trans. So the differences seen in relaxed potential energy scans ${ }^{28}$ do not translate into actual differences in thermochemical parameters in this case. What differences that do exist are a reflection of our treatment, viz. using unscaled harmonic frequencies, $\bar{\nu}$, and anharmonicity coefficients, $x_{i i}$, to compute the vibrational contributions to $S^{\ominus}, C_{p}^{\ominus}$ and $\left(H_{T}^{\ominus}-H_{0}^{\ominus}\right)$, and of course any deficiences in the DFs themselves.

The Burcat database ${ }^{37}$ reports values based on a RRHO treatment at the B3LYP/6$31 \mathrm{G}(\mathrm{d})$ level with frequencies scaled by 0.96 whilst Goldsmith and colleagues used B3LYP/6$311++\mathrm{G}(\mathrm{d}, \mathrm{p})$ frequencies and relaxed potential energy scans at B3LYP/6-31+G(d,p) to ac- 


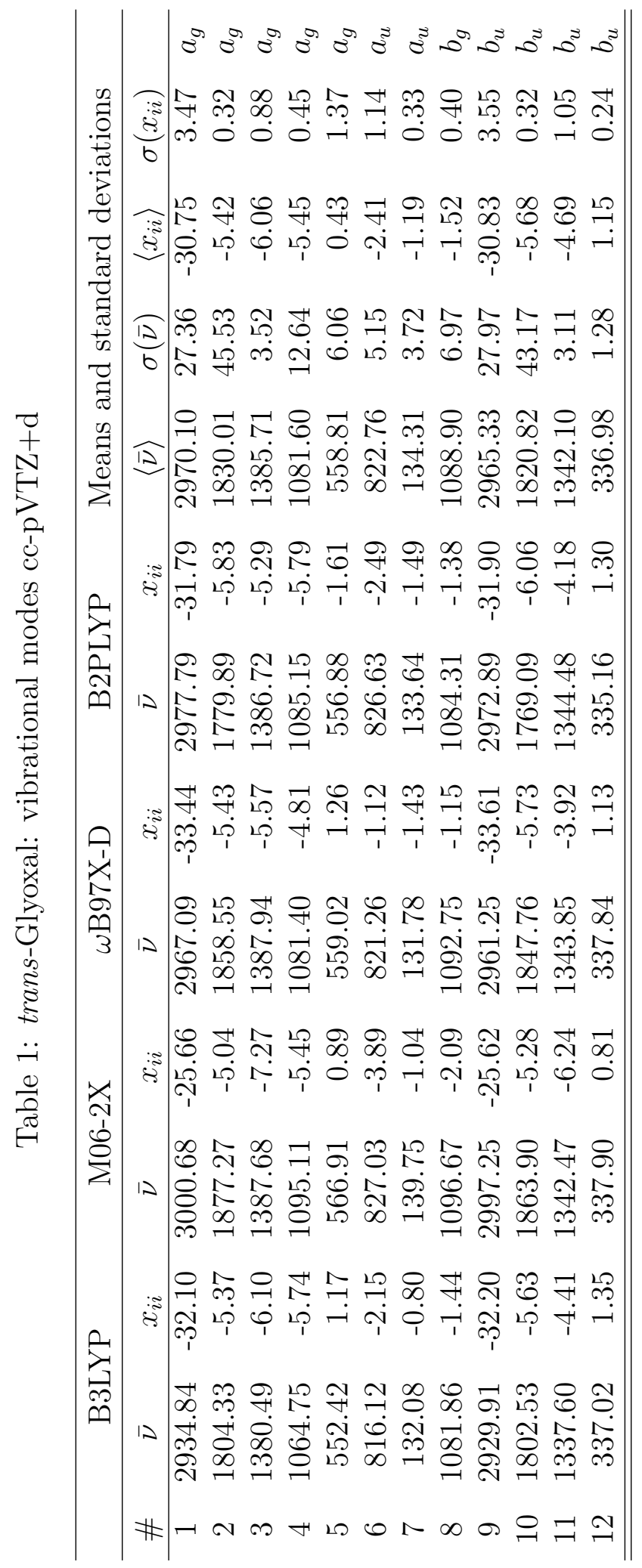


Table 2: Potential energy barrier / $\mathrm{kJ} \mathrm{mol}^{-1}$

\begin{tabular}{|c|c|c|c|c|}
\hline Scan & $6-31 \mathrm{G}(\mathrm{d}, \mathrm{p})$ & $6-311++\mathrm{G}(\mathrm{d}, \mathrm{p})$ & cc-pVTZ+d & def2QZVpp \\
\hline B3LYP & 28.32 & 24.92 & 25.94 & 24.63 \\
\hline M06-2X & 29.38 & 26.57 & 27.03 & 26.03 \\
\hline$\omega \mathrm{B} 97 \mathrm{X}-\mathrm{D}$ & 27.62 & 24.57 & 25.08 & 24.14 \\
\hline B2PLYP & 28.72 & 25.23 & 26.44 & 25.13 \\
\hline$\langle E\rangle$ & 28.51 & 25.32 & 26.12 & 24.98 \\
\hline$\sigma$ & 0.74 & 0.87 & 0.83 & 0.81 \\
\hline
\end{tabular}

Table 3: Entropy, isobaric heat capacity and enthalpy function at $298.15 \mathrm{~K}$

\begin{tabular}{lcrrc}
\hline & B3LYP & M06-2X & $\omega$ B97X-D & B2LYP \\
\hline \multirow{4}{c}{$S^{\ominus} / \mathrm{J} \mathrm{K}^{-1}$} & $\mathrm{~mol}^{-1}$ \\
vib & 271.92 & 271.28 & 272.09 & 272.51 \\
vib+hr & 271.87 & 271.15 & 271.73 & 271.72 \\
\hline \multicolumn{4}{c}{$C_{p}^{\ominus} / \mathrm{J} \mathrm{K}^{-1} \mathrm{~mol}^{-1}$} \\
vib & 59.52 & 59.19 & 59.67 & 59.78 \\
vib+hr & 59.82 & 59.33 & 59.59 & 59.73 \\
\hline \multicolumn{5}{c}{$\left(H_{T}^{\ominus}-H_{0}^{\ominus}\right) / \mathrm{kJ} \mathrm{mol}^{-1}$} \\
vib & 13.61 & 13.54 & 13.63 & 13.67 \\
vib+hr & 13.61 & 13.53 & 13.59 & 13.60 \\
\hline \hline
\end{tabular}

count for hindered rotors. Barone ${ }^{38}$ quotes a value from his own second-order perturbative vibrational treatment based on B3LYP/6-31G(d) calculations plus hindered rotor correction from Ayala and Schlegel ${ }^{39}$ while the Thermodynamics Research Center has a set of recommendations. ${ }^{40}$

All of which are in good agreement, Table 4, with our averaged entropy, Table 5, with our average isobaric heat capacity, Table 6, and with the enthalpy function, Table 7; clearly this molecule does not present any challenge since all the various approaches give rise to the same results. From which one might conclude that its inclusion in databases set up for the purposes of validation is possibly superfluous.

Exactly the same conclusion can be reached for ethanal, $\mathrm{H}_{3} \mathrm{CCHO}$, for which a multi-DFT approach yields $\left\langle S^{\ominus}\right\rangle=263.84 \pm 0.04$ and $\left\langle C_{p}^{\ominus}\right\rangle=53.88 \pm 0.19$ as compared to literature ${ }^{41}$ values of $263.95 \pm 0.22$ and $55.32 \pm 0.08$, respectively, all in $\mathrm{J} \mathrm{K}^{-1} \mathrm{~mol}^{-1}$ at $298.15 \mathrm{~K}$.

The uncertainties $(\sigma)$ increase gradually and consistently for both $S^{\ominus}$ and $\left(H_{T}^{\ominus}-H_{0}^{\ominus}\right)$ 
Table 4: trans-Glyoxal: comparison with literature at $298.15 \mathrm{~K}$

\begin{tabular}{lll}
\hline$S^{\ominus} / \mathrm{J} \mathrm{K}^{-1} \mathrm{~mol}^{-1}$ & $C_{p}^{\ominus} / \mathrm{J} \mathrm{K}^{-1} \mathrm{~mol}^{-1}$ & $\left(H_{T}^{\ominus}-H_{0}^{\ominus}\right) / \mathrm{kJ} \mathrm{mol}^{-1}$ \\
\hline $270.3 \pm 3.8^{4}$ & $60.7 \pm 3.3^{a 4}$ & \\
$272.483^{37}$ & $60.49^{37}$ & \\
$271.89^{38,39}$ & & $13.67^{40}$ \\
$272.44^{40}$ & $60.23^{40}$ & $13.58 \pm 0.04^{b}$ \\
$271.62 \pm 0.32^{b}$ & $59.62 \pm 0.21^{b}$ & \\
\hline \hline${ }^{a} 300 \mathrm{~K}$ & ${ }^{b}$ This work
\end{tabular}

Table 5: trans-Glyoxal: variation of $S^{\ominus} / \mathrm{J} \mathrm{K}^{-1} \mathrm{~mol}^{-1}$

\begin{tabular}{ccccccc}
\hline$T / \mathrm{K}$ & B3LYP & M06-2X & $\omega$ B97X-D & B2PLYP & $\left\langle S^{\ominus}\right\rangle$ & $\sigma$ \\
\hline 298.15 & 271.87 & 271.15 & 271.73 & 271.72 & 271.62 & 0.32 \\
300 & 272.24 & 271.51 & 272.10 & 272.09 & 271.99 & 0.32 \\
400 & 290.93 & 290.04 & 290.72 & 290.76 & 290.61 & 0.39 \\
500 & 307.73 & 306.68 & 307.44 & 307.55 & 307.35 & 0.46 \\
600 & 323.13 & 321.96 & 322.77 & 322.96 & 322.71 & 0.52 \\
700 & 337.32 & 336.07 & 336.89 & 337.17 & 336.86 & 0.56 \\
800 & 350.43 & 349.11 & 349.91 & 350.30 & 349.94 & 0.59 \\
900 & 362.54 & 361.20 & 361.96 & 362.44 & 362.04 & 0.61 \\
1000 & 373.78 & 372.42 & 373.13 & 373.70 & 373.26 & 0.63 \\
1100 & 384.24 & 382.86 & 383.53 & 384.19 & 383.71 & 0.65 \\
1200 & 394.00 & 392.62 & 393.23 & 393.97 & 393.46 & 0.66 \\
1300 & 403.15 & 401.76 & 402.33 & 403.14 & 402.60 & 0.68 \\
1400 & 411.74 & 410.36 & 410.88 & 411.76 & 411.19 & 0.69 \\
1500 & 419.85 & 418.46 & 418.94 & 419.88 & 419.28 & 0.70 \\
1600 & 427.50 & 426.12 & 426.56 & 427.56 & 426.94 & 0.71 \\
1800 & 441.66 & 440.29 & 440.66 & 441.76 & 441.09 & 0.73 \\
2000 & 454.50 & 453.15 & 453.45 & 454.64 & 453.94 & 0.75 \\
\hline \hline
\end{tabular}


Table 6: trans-Glyoxal: variation of $C_{p}^{\ominus} / \mathrm{J} \mathrm{K}^{-1} \mathrm{~mol}^{-1}$

\begin{tabular}{ccccccc}
\hline$T / \mathrm{K}$ & B3LYP & M06-2X & $\omega$ B97X-D & B2PLYP & $\left\langle C_{p}^{\ominus}\right\rangle$ & $\sigma$ \\
\hline 298.15 & 59.82 & 59.33 & 59.59 & 59.73 & 59.62 & 0.21 \\
300 & 60.01 & 59.52 & 59.78 & 59.92 & 59.81 & 0.21 \\
400 & 70.44 & 69.79 & 70.16 & 70.38 & 70.19 & 0.29 \\
500 & 80.28 & 79.58 & 79.92 & 80.29 & 80.02 & 0.34 \\
600 & 88.65 & 88.03 & 88.20 & 88.74 & 88.41 & 0.34 \\
700 & 95.40 & 94.91 & 94.87 & 95.55 & 95.18 & 0.34 \\
800 & 100.74 & 100.39 & 100.14 & 100.93 & 100.55 & 0.35 \\
900 & 104.96 & 104.72 & 104.32 & 105.18 & 104.80 & 0.37 \\
1000 & 108.33 & 108.18 & 107.68 & 108.58 & 108.19 & 0.38 \\
1100 & 111.06 & 110.97 & 110.41 & 111.33 & 110.94 & 0.39 \\
1200 & 113.31 & 113.26 & 112.67 & 113.58 & 113.21 & 0.38 \\
1300 & 115.17 & 115.17 & 114.56 & 115.46 & 115.09 & 0.38 \\
1400 & 116.75 & 116.77 & 116.15 & 117.05 & 116.68 & 0.38 \\
1500 & 118.09 & 118.14 & 117.52 & 118.41 & 118.04 & 0.37 \\
1600 & 119.24 & 119.31 & 118.70 & 119.58 & 119.21 & 0.37 \\
1800 & 121.11 & 121.23 & 120.61 & 121.49 & 121.11 & 0.37 \\
2000 & 122.56 & 122.72 & 122.10 & 122.98 & 122.59 & 0.37 \\
\hline \hline
\end{tabular}

whilst $C_{p}^{\ominus}$ shows an almost constant uncertainty whereas the Goldsmith data shows more variability ${ }^{4}$ although still in excellent agreement at $1,500 \mathrm{~K}$, for example, $C_{p}^{\ominus}=118.0 \pm 0.8$ versus $C_{p}^{\ominus}=118.04 \pm 0.37 \mathrm{~J} \mathrm{~K}^{-1} \mathrm{~mol}^{-1}$.

\section{Summary}

All the functionals tested give a good consistent account for this closed-shell molecule with clearly defined conformers which are not near in energy. The computed frequencies, anharmonicities and rotational barriers are all very similar which in term explains the virtually indistinguishable results for the entropy, isobaric heat capacity and enthalpy function. Hence, in this particular case the uncertainties delineated by Goldsmith et al. are too pessimistic — being too large by factors of $5-10$. 
Table 7: trans-Glyoxal: variation of $\left(H_{T}^{\ominus}-H_{0}^{\ominus}\right) / \mathrm{kJ} \mathrm{mol}^{-1}$

\begin{tabular}{ccccccc}
\hline$T / \mathrm{K}$ & B3LYP & M06-2X & $\omega$ B97X-D & B2PLYP & $\left\langle H_{T}^{\ominus}-H_{0}^{\ominus}\right\rangle$ & $\sigma$ \\
\hline 298.15 & 13.61 & 13.53 & 13.59 & 13.60 & 13.58 & 0.04 \\
300 & 13.72 & 13.64 & 13.70 & 13.71 & 13.69 & 0.04 \\
400 & 20.25 & 20.10 & 20.20 & 20.22 & 20.19 & 0.06 \\
500 & 27.79 & 27.58 & 27.71 & 27.76 & 27.71 & 0.09 \\
600 & 36.25 & 35.97 & 36.13 & 36.23 & 36.15 & 0.13 \\
700 & 45.46 & 45.13 & 45.29 & 45.45 & 45.33 & 0.16 \\
800 & 55.28 & 54.90 & 55.05 & 55.29 & 55.13 & 0.19 \\
900 & 65.57 & 65.17 & 65.28 & 65.60 & 65.41 & 0.21 \\
1000 & 76.24 & 75.82 & 75.89 & 76.29 & 76.06 & 0.24 \\
1100 & 87.22 & 86.78 & 86.80 & 87.29 & 87.02 & 0.27 \\
1200 & 98.44 & 97.99 & 97.95 & 98.54 & 98.23 & 0.30 \\
1300 & 109.86 & 109.41 & 109.31 & 109.99 & 109.64 & 0.33 \\
1400 & 121.46 & 121.01 & 120.85 & 121.62 & 121.24 & 0.36 \\
1500 & 133.20 & 132.76 & 132.53 & 133.39 & 132.97 & 0.39 \\
1600 & 145.07 & 144.63 & 144.35 & 145.29 & 144.84 & 0.42 \\
1800 & 169.11 & 168.69 & 168.28 & 169.41 & 168.87 & 0.49 \\
2000 & 193.48 & 193.09 & 192.56 & 193.86 & 193.25 & 0.56 \\
\hline \hline
\end{tabular}

\section{Case study II: formyloxy oxomethyl, $\mathrm{HC}(\mathrm{O}) \mathrm{OC}^{\bullet} \mathrm{O}$}

The radical of formic acid anhydride ${ }^{53}$ presents a different challenge to that outlined above for glyoxal inasmuch as now there are low-lying conformers to the ground state which can be classified as syn/anti with respect to the $\mathrm{OCOC}^{\bullet} / \mathrm{COC}^{\bullet} \mathrm{O}$ dihedrals, Fig. 1. The $a a$, as and ss conformers lie at $+0.67,+7.2$ and $+10.6 \mathrm{~kJ} \mathrm{~mol}^{-1}$ respectively, from $\mathrm{G}^{54}$ calculations, however in one sense these more accurate results can be misleading since for the purposes of computing uncertainties in thermochemical parameters the same ground state must be chosen for the various methods. Here, M06-2X has the $s a$ conformer as the lowest whereas B3LYP, $\omega$ B97X-D and B2PLYP all have $a a$ as the lowest. The aa-as zero-point corrected electronic energy differences for these methods, including MN12-L and PBE0-DH, never exceeds $1.4 \mathrm{~kJ} \mathrm{~mol}^{-1}$; this very small difference accounts for the variability encountered.

Calculated geometry energy offsets ${ }^{55}$ for $a a-\mathrm{HC}(\mathrm{O}) \mathrm{OC} \mathrm{C}^{\bullet} \mathrm{O}$ based on a proxy reference B2PLYP/aug-cc-pV5Z geometry do indeed show that the methods can be ranked in the order B3LYP > $\omega$ B97X-D > MN15 > M06-2X > PBE-0DH > MN12-L. 


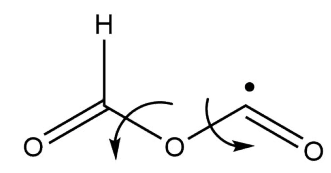

Figure 1: anti/anti conformer of formyloxy oxomethyl

The barrier to rotation about \#1 $(a a \rightarrow s a)$ are very consistent for all four methods at $26.1 \pm 0.4 \mathrm{~kJ} \mathrm{~mol}^{-1}$ as indeed they are about \#2 (aa $\left.\rightarrow a s\right)$ at $32.2 \pm 0.6 \mathrm{~kJ} \mathrm{~mol}^{-1}$

\section{Frequencies}

Geometry optimisation indicates a ${ }^{2} A^{\prime}$ ground state of $\mathrm{C}_{S}$ symmetry. All the functionals give concordant results, not just for the frequencies, but also for the anharmonic coefficients, Table 8; where there is divergence, for example for $\bar{\nu}_{12}$, with an anharmonicity coefficient of 2-3 times larger than the norm, it effectively has little impact since this frequency, and the preceeding one, will be replaced by a hindered rotor treatment.

Table 8: $a a-\mathrm{HC}(\mathrm{O}) \mathrm{OC}{ }^{\bullet} \mathrm{O}$ : vibrational modes at cc-pVTZ $+\mathrm{d}$

\begin{tabular}{|c|c|c|c|c|c|c|c|c|c|}
\hline \multicolumn{2}{|c|}{ B3LYP } & \multicolumn{2}{|c|}{ M06-2X } & \multicolumn{2}{|c|}{$\omega \mathrm{B} 97 \mathrm{X}-\mathrm{D}$} & \multicolumn{2}{|c|}{ B2PLYP } & \multirow[b]{2}{*}{$\langle\bar{\nu}\rangle$} & \multirow[b]{2}{*}{ 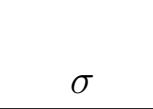 } \\
\hline $\bar{\nu}$ & $x_{i i}$ & $\bar{\nu}$ & $x_{i i}$ & $\bar{\nu}$ & $x_{i i}$ & $\bar{\nu}$ & $x_{i i}$ & & \\
\hline 3042.97 & -62.76 & 3090.23 & -55.38 & 3061.32 & -60.97 & 3080.55 & -61.40 & 3068.77 & $20.98 a^{\prime}$ \\
\hline 1933.28 & -7.05 & 2000.60 & -7.37 & 1979.35 & -6.27 & 1911.97 & -6.56 & 1956.30 & $40.78 a^{\prime}$ \\
\hline 1855.94 & -5.89 & 1914.77 & -5.55 & 1896.74 & -4.51 & 1835.61 & -5.84 & 1875.76 & $36.36 a^{\prime}$ \\
\hline 1381.62 & -9.90 & 1403.64 & -7.98 & 1391.66 & -10.11 & 1390.73 & -9.68 & 1391.91 & $9.03 a^{\prime}$ \\
\hline 1083.24 & -3.85 & 1131.11 & -3.74 & 1122.66 & -3.82 & 1088.85 & -3.90 & 1106.46 & $23.94 a^{\prime}$ \\
\hline 997.89 & -13.78 & 1085.99 & -9.67 & 1059.46 & -8.58 & 1010.78 & -8.61 & 1038.53 & $41.28 a^{\prime}$ \\
\hline 684.23 & -0.53 & 696.82 & -0.51 & 696.97 & -0.17 & 684.31 & -0.37 & 690.58 & $7.29 a^{\prime}$ \\
\hline 518.79 & -2.16 & 542.21 & -1.90 & 534.21 & -1.69 & 520.02 & -2.01 & 528.81 & $11.35 a^{\prime}$ \\
\hline 255.14 & -0.64 & 267.40 & -0.73 & 259.29 & -0.45 & 256.73 & -0.65 & 259.64 & $5.45 a^{\prime}$ \\
\hline 1032.27 & -2.76 & 1052.52 & -3.55 & 1046.50 & -2.21 & 1035.18 & -2.75 & 1041.62 & $9.51 a^{\prime \prime}$ \\
\hline 250.99 & -2.17 & 256.24 & -2.70 & 253.77 & -1.89 & 252.13 & -2.22 & 253.28 & $2.28 a^{\prime \prime}$ \\
\hline 129.63 & 0.79 & 128.70 & -1.35 & 129.76 & 22.69 & 128.04 & -6.53 & 129.03 & $0.81 a^{\prime \prime}$ \\
\hline
\end{tabular}

\section{Entropy and isobaric heat capacity}

Two modes, \#11 and \#12, with well-behaved relaxed potential energy scans are treated as hindered rotors which changes the $\mathrm{RR}$ anharmonic values considerably, for example, 
$\Delta S^{\ominus}(298.15 \mathrm{~K})$ by $+9.1 \mathrm{~J} \mathrm{~K}^{-1} \mathrm{~mol}^{-1}$. However, all the methods give essentially the same result $\left\langle S^{\ominus}\right\rangle=309.9 \pm 0.6$ at $298.15 \mathrm{~K}$ and $508.2 \pm 1.7 \mathrm{~J} \mathrm{~K}^{-1} \mathrm{~mol}^{-1}$ at 2,000 K, Table 9, with a near monotonic increase in uncertainty with temperature.

Table 9: $a a-\mathrm{HC}(\mathrm{O}) \mathrm{OC}^{\bullet} \mathrm{O}$ : variation of $S^{\ominus} / \mathrm{J} \mathrm{K}^{-1} \mathrm{~mol}^{-1}$

\begin{tabular}{ccccccc}
\hline$T / \mathrm{K}$ & B3LYP & M06-2X & $\omega$ B97X-D & B2PLYP & $\left\langle S^{\ominus}\right\rangle$ & $\sigma$ \\
\hline 298.15 & 309.87 & 309.72 & 309.24 & 310.71 & 309.89 & 0.61 \\
300 & 310.33 & 310.17 & 309.69 & 311.16 & 310.34 & 0.61 \\
400 & 333.12 & 332.44 & 332.09 & 333.61 & 332.82 & 0.68 \\
500 & 352.91 & 351.71 & 351.59 & 353.16 & 352.34 & 0.81 \\
600 & 370.51 & 368.87 & 368.95 & 370.58 & 369.73 & 0.94 \\
700 & 386.34 & 384.35 & 384.60 & 386.29 & 385.40 & 1.07 \\
800 & 400.7 & 398.43 & 398.81 & 400.56 & 399.63 & 1.17 \\
900 & 413.82 & 411.33 & 411.80 & 413.61 & 412.64 & 1.26 \\
1000 & 425.85 & 423.19 & 423.73 & 425.6 & 424.59 & 1.33 \\
1100 & 436.96 & 434.16 & 434.75 & 436.66 & 435.63 & 1.39 \\
1200 & 447.26 & 444.34 & 444.96 & 446.93 & 445.87 & 1.44 \\
1300 & 456.84 & 453.84 & 454.47 & 456.49 & 455.41 & 1.48 \\
1400 & 465.81 & 462.72 & 463.37 & 465.43 & 464.33 & 1.52 \\
1500 & 474.22 & 471.06 & 471.72 & 473.82 & 472.71 & 1.55 \\
1600 & 482.14 & 478.92 & 479.58 & 481.72 & 480.59 & 1.58 \\
1800 & 496.72 & 493.39 & 494.03 & 496.26 & 495.10 & 1.64 \\
2000 & 509.89 & 506.45 & 507.08 & 509.37 & 508.20 & 1.69 \\
\hline \hline
\end{tabular}

The isobaric heat capacity is remarkably consistent across all four functionals, Table 10; at its worst the standard deviation is $1 \%$ but follows a more complex variation with increasing temperature as opposed to the case for the entropy for which the uncertainty increases in a more straightforward manner. The enthalpy function, Table 11, is also unremarkably consistent with a steadily declining percentage error with increasing temperature.

\section{Summary}

For this open-shell species the tested functionals have frequencies, anharmonicities and rotational barriers in close agreement, Table 8 - this will lead to concordant values for the thermochemical parameters, Tables 9-11. Although the presence of two hindered rotors, which are fortunately well-behaved, changes the RR-HO values considerably the final values 
Table 10: $a a-\mathrm{HC}(\mathrm{O}) \mathrm{OC}^{\bullet} \mathrm{O}$ : variation of $C_{p}^{\ominus} / \mathrm{J} \mathrm{K}^{-1} \mathrm{~mol}^{-1}$

\begin{tabular}{ccccccc}
\hline$T / \mathrm{K}$ & B3LYP & M06-2X & $\omega$ B97X-D & B2PLYP & $\left\langle C_{p}^{\ominus}\right\rangle$ & $\sigma$ \\
\hline 298.15 & 74.03 & 72.64 & 72.68 & 72.81 & 73.04 & 0.66 \\
300 & 74.23 & 72.82 & 72.88 & 73.01 & 73.24 & 0.67 \\
400 & 84.44 & 82.26 & 83.11 & 83.29 & 83.28 & 0.90 \\
500 & 93.00 & 90.59 & 91.71 & 91.99 & 91.82 & 0.99 \\
600 & 99.94 & 97.57 & 98.70 & 99.07 & 98.82 & 0.98 \\
700 & 105.40 & 103.22 & 104.24 & 104.67 & 104.38 & 0.91 \\
800 & 109.65 & 107.69 & 108.56 & 109.04 & 108.74 & 0.83 \\
900 & 112.94 & 111.20 & 111.91 & 112.43 & 112.12 & 0.74 \\
1000 & 115.50 & 113.96 & 114.51 & 115.06 & 114.76 & 0.67 \\
1100 & 117.51 & 116.13 & 116.56 & 117.13 & 116.83 & 0.61 \\
1200 & 119.11 & 117.87 & 118.18 & 118.77 & 118.48 & 0.56 \\
1300 & 120.41 & 119.27 & 119.48 & 120.08 & 119.81 & 0.53 \\
1400 & 121.48 & 120.42 & 120.54 & 121.16 & 120.90 & 0.50 \\
1500 & 122.38 & 121.37 & 121.42 & 122.05 & 121.81 & 0.49 \\
1600 & 123.14 & 122.17 & 122.15 & 122.80 & 122.57 & 0.49 \\
1800 & 124.41 & 123.46 & 123.33 & 124.00 & 123.80 & 0.50 \\
2000 & 125.44 & 124.45 & 124.23 & 124.94 & 124.77 & 0.54 \\
\hline \hline
\end{tabular}

Table 11: $a a-\mathrm{HC}(\mathrm{O}) \mathrm{OC} \mathrm{C}^{\bullet}$ : variation of $\left(H_{T}^{\ominus}-H_{0}^{\ominus}\right) / \mathrm{kJ} \mathrm{mol}^{-1}$

\begin{tabular}{ccccccc}
\hline$T / \mathrm{K}$ & B3LYP & M06-2X & $\omega$ B97X-D & B2PLYP & $\left\langle H_{T}^{\ominus}-H_{0}^{\ominus}\right\rangle$ & $\sigma$ \\
\hline 298.15 & 16.46 & 16.30 & 16.12 & 16.32 & 16.30 & 0.14 \\
300 & 16.60 & 16.44 & 16.26 & 16.45 & 16.44 & 0.14 \\
400 & 24.54 & 24.20 & 24.07 & 24.28 & 24.27 & 0.20 \\
500 & 33.43 & 32.85 & 32.82 & 33.05 & 33.04 & 0.28 \\
600 & 43.09 & 42.27 & 42.36 & 42.62 & 42.59 & 0.37 \\
700 & 53.37 & 52.32 & 52.51 & 52.82 & 52.76 & 0.46 \\
800 & 64.13 & 62.87 & 63.16 & 63.51 & 63.42 & 0.54 \\
900 & 75.26 & 73.82 & 74.19 & 74.59 & 74.47 & 0.62 \\
1000 & 86.69 & 85.08 & 85.52 & 85.97 & 85.82 & 0.69 \\
1100 & 98.34 & 96.59 & 97.07 & 97.58 & 97.40 & 0.75 \\
1200 & 110.17 & 108.29 & 108.81 & 109.38 & 109.16 & 0.81 \\
1300 & 122.15 & 120.15 & 120.70 & 121.32 & 121.08 & 0.86 \\
1400 & 134.25 & 132.13 & 132.70 & 133.38 & 133.12 & 0.91 \\
1500 & 146.44 & 144.22 & 144.80 & 145.54 & 145.25 & 0.96 \\
1600 & 158.71 & 156.40 & 156.97 & 157.79 & 157.47 & 1.01 \\
1800 & 183.47 & 180.97 & 181.53 & 182.47 & 182.11 & 1.10 \\
2000 & 208.46 & 205.76 & 206.28 & 207.36 & 206.97 & 1.20 \\
\hline \hline
\end{tabular}


for all four functionals are in very good agreement. A case can be made for recommending $S^{\ominus}=309.9 \pm 1.2$ and $C_{p}^{\ominus}=73.04 \pm 1.32$ both in $\mathrm{J} \mathrm{K}^{-1} \mathrm{~mol}^{-1}$ and $\left(H_{T}^{\ominus}-H_{0}^{\ominus}\right)=16.30 \pm 0.28$ $\mathrm{kJ} \mathrm{mol}^{-1}$ all at $298.15 \mathrm{~K}$, where the uncertainties are $\pm 2 \sigma$. The Goldsmith approach ${ }^{4}$ would give rise much larger uncertainties of $\pm 4.6, \pm 3.3 \mathrm{~J} \mathrm{~K}^{-1} \mathrm{~mol}^{-1}$ and $\pm 0.54 \mathrm{~kJ} \mathrm{~mol}{ }^{-1}$, respectively.

\section{Case study III: $\mathrm{H}_{3} \mathrm{COC}^{\bullet}(\mathrm{O})_{2}$}

This species, methoxy oxomethoxy or the methyl carbonate radical, can give rise to problematic vibrational spectra which is particularly evident for double-hybrid functionals but has very little impact on derived values such as entropy, etc as pointed out recently. ${ }^{43}$ It has featured in recent experimental and modelling work on the reaction of alkyl carbonate radicals with lipid components, ${ }^{44}$ on the pyrolysis and combustion ${ }^{45-48}$ of dimethyl carbonate ${ }^{49}$ and is a product in the thermal decomposition of methyl fluoroformyl peroxycarbonate. ${ }^{50}$

\section{Frequencies}

Geometry optimisation shows a structure with $C_{s}$ symmetry and electronic state ${ }^{2} A^{\prime}$; a $T_{1}$ diagnostic $^{51}$ of 0.029 indicates that single-reference methods are probably sufficient. Close inspection of the frequencies indicates that not all the functionals return consistent anharmonicities with M06-2X the culprit in this set, Table 12; the very large anharmonicity exhibited by BMK and MN12-L for $\bar{\nu}_{18}$ are inconsequential since this mode will be replaced by a hindered rotor.

\section{Entropy and isobaric heat capacity}

Gaussian-16 identifies two hindered rotors, modes \#17 and \#18, which correspond to torsions about the $\mathrm{C}-\mathrm{O}-\mathrm{C}-\mathrm{O}$ dihedral and the methyl rotor whose reduced barrier heights, $(V / \mathrm{R} T)$, are 6.2 and 1.2 respectively, at room temperature.

Firstly, we consider these effects with the functional B3LYP and the basis set cc-pVTZ + d, 


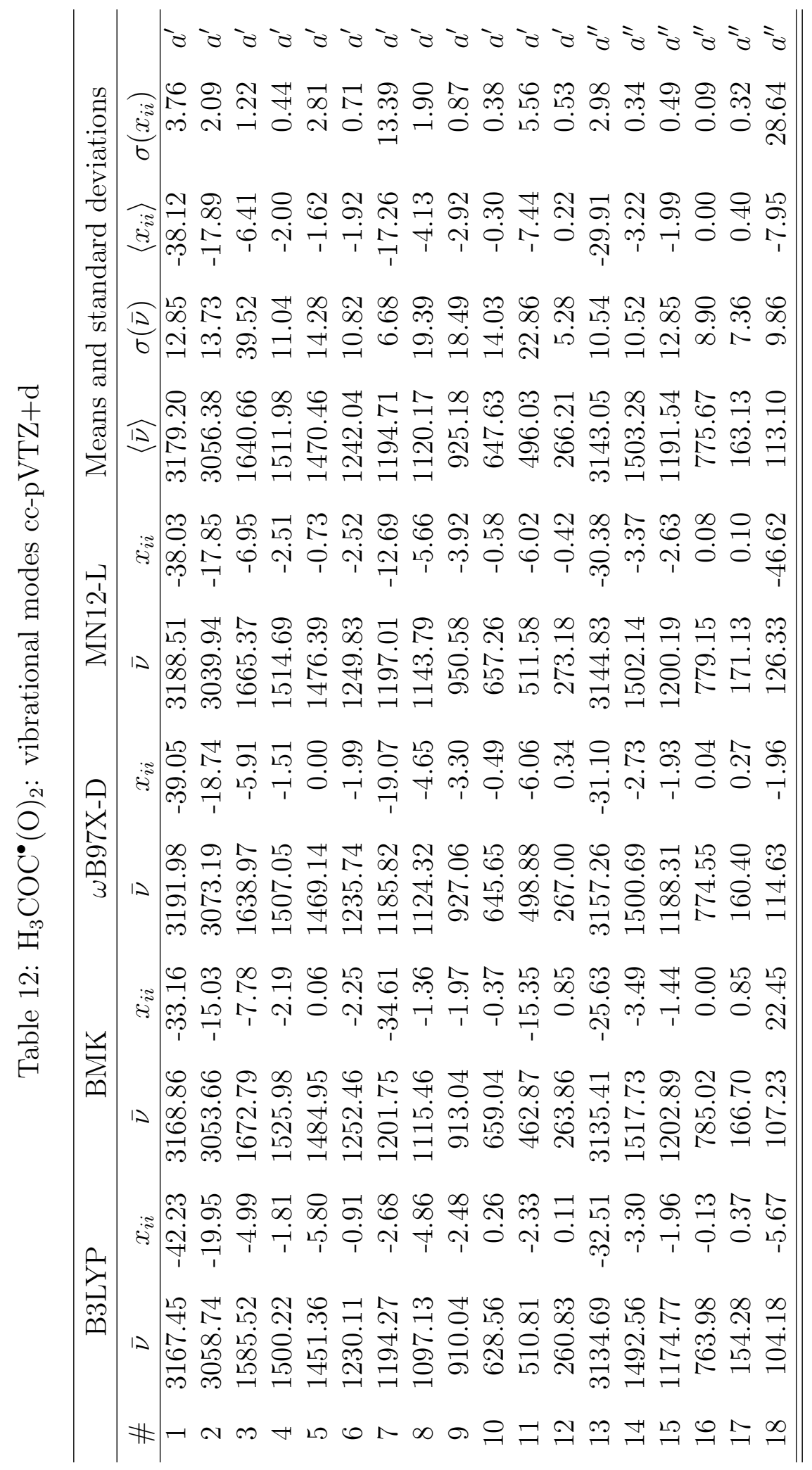


Table 13. The most complete treatment (c) uses anharmonic frequencies and two hindered rotors as opposed to a conventional RRHO approach (a); options (d) and (e) use different MultiWell/Thermo approximations to the nearly 'free' methyl rotor. At room temperature the entropy scarcely changes, $(\mathrm{a}) \rightarrow(\mathrm{c})$, and the different calculational approaches to account for the nearly free methyl rotor give effectively the same answer, $(d) \rightarrow(e)$. Thus the entropies show very little dependence on the particular methodology but the heat capacity and the enthalpy function demonstrate much more sensitivity.

Table 13: Entropy, isobaric heat capacity / $\mathrm{J} \mathrm{K}^{-1} \mathrm{~mol}^{-1}$, enthalpy function $/ \mathrm{kJ} \mathrm{mol}^{-1}$

\begin{tabular}{|c|c|c|c|c|}
\hline & $S^{\ominus}$ & $C_{p}^{\ominus}$ & $\left(H_{T}^{\ominus}-H_{0}^{\ominus}\right)$ & B3LYP/cc-pVTZ+d \\
\hline \multicolumn{5}{|c|}{$298.15 \mathrm{~K}$} \\
\hline (a) & 312.5 & 76.61 & 16.31 & Scaled vibrations \\
\hline (b) & 313.7 & 71.89 & 16.22 & Anharmonics \\
\hline (c) & 312.8 & 74.25 & 16.41 & Anharmonics +2 HRs \\
\hline (d) & 312.7 & 73.55 & 16.15 & Scaled vibrations + 'hrb' methyl rotor \\
\hline$(\mathrm{e})$ & 313.2 & 72.62 & 15.73 & Scaled vibrations + 'qro' methyl rotor \\
\hline \multicolumn{5}{|c|}{$2,000 \mathrm{~K}$} \\
\hline (a) & 555.7 & 169.3 & 245.2 & Scaled vibrations \\
\hline (b) & 542.7 & 162.0 & 253.3 & Anharmonics \\
\hline (c) & 551.3 & 164.8 & 258.3 & Anharmonics +2 HRs \\
\hline (d) & 542.8 & 165.2 & 251.3 & Scaled vibrations + 'hrb' methyl rotor \\
\hline$(\mathrm{e})$ & 542.8 & 165.1 & 250.6 & Scaled vibrations + 'qro' methyl rotor \\
\hline
\end{tabular}

Secondly, we employ different functionals BMK, M06-2X, $\omega$ B97X-D, and MN12-L in comparison to B3LYP all at cc-pVTZ+d using unscaled anharmonic frequencies and relaxed potential energy scans for the two hindered rotors, Table 14. For M06-2X a relaxed potential energy scan about the COCO dihedral misbehaves and is replaced by a B3LYP scan but the symmetric methyl rotor is well-behaved. We note in passing that earlier studies calculated M06-2X and MN12-L frequencies but probably utilised B3LYP/6-31G(d) scans in their treatment of $1 \mathrm{D}$ hindered rotors. ${ }^{52}$

The results show some scatter, $S^{\ominus}=311.2 \pm 1.6$ and $C_{p}^{\ominus}=74.54 \pm 1.10$ at $298.15 \mathrm{~K}$ and $S^{\ominus}=550.7 \pm 1.4$ and $C_{p}^{\ominus}=166.06 \pm 2.54$ at $2,000 \mathrm{~K}$, all in $\mathrm{J} \mathrm{K}^{-1} \mathrm{~mol}^{-1}$, see Tables $14-15$. Scaling the M06-2X harmonic frequencies by 0.985 as recommended ${ }^{57}$ (but for aug-cc-pVTZ) 
vis-à-vis B3LYP does alter the entropy and heat capacity by +0.6 and $+0.8 \mathrm{~J} \mathrm{~K}^{-1} \mathrm{~mol}^{-1}$, respectively, and the enthalpy function by $+0.1 \mathrm{~kJ} \mathrm{~mol}^{-1}$ thus worsening if anything the agreement with B3LYP. Given the more pronounced anharmonicities shown by M06-2X (these are shared by MN12-L and MN15 $5^{21}$ but to a lesser extent) its contribution is replaced by BMK in the final recommendations.

Table 14: $\mathrm{H}_{3} \mathrm{COC}^{\bullet}(\mathrm{O})_{2}: S^{\ominus} / \mathrm{J} \mathrm{K}^{-1} \mathrm{~mol}^{-1}$

\begin{tabular}{ccccccc}
\hline$T / \mathrm{K}$ & B3LYP & BMK & $\omega$ B97X-D & MN12-L & $\left\langle S^{\ominus}\right\rangle$ & $\sigma$ \\
\hline 298.15 & 312.80 & 312.23 & 310.08 & 309.47 & 311.15 & 1.62 \\
300 & 313.26 & 312.69 & 310.55 & 309.92 & 311.61 & 1.62 \\
400 & 336.76 & 336.19 & 334.40 & 333.14 & 335.12 & 1.66 \\
500 & 358.24 & 357.66 & 355.97 & 354.36 & 356.56 & 1.75 \\
600 & 378.09 & 377.55 & 375.82 & 374.01 & 376.37 & 1.85 \\
700 & 396.45 & 396.05 & 394.20 & 392.26 & 394.74 & 1.92 \\
800 & 413.47 & 413.26 & 411.27 & 409.24 & 411.81 & 1.98 \\
900 & 429.27 & 429.28 & 427.15 & 425.06 & 427.69 & 2.02 \\
1000 & 443.98 & 444.20 & 441.97 & 439.84 & 442.50 & 2.04 \\
1100 & 457.72 & 458.13 & 455.84 & 453.68 & 456.34 & 2.04 \\
1200 & 470.60 & 471.15 & 468.85 & 466.69 & 469.32 & 2.01 \\
1300 & 482.70 & 483.36 & 481.11 & 478.93 & 481.53 & 1.97 \\
1400 & 494.11 & 494.84 & 492.67 & 490.49 & 493.03 & 1.92 \\
1500 & 504.89 & 505.65 & 503.62 & 501.43 & 503.90 & 1.85 \\
1600 & 515.11 & 515.88 & 514.00 & 511.81 & 514.20 & 1.77 \\
1800 & 534.06 & 534.75 & 533.28 & 531.10 & 533.30 & 1.58 \\
2000 & 551.30 & 551.84 & 550.85 & 548.68 & 550.67 & 1.39 \\
\hline \hline
\end{tabular}

The gas-phase entropy reported in the literature varies considerably as does the isobaric heat capacity although to a lesser extent, Table 17. Our result for the entropy agrees best with a multi-structural approach ${ }^{36}$ based on MN12-L/ma-TZVP geometries and frequencies $^{52}$ but B3LYP/6-31G(d) potential energy scans; ${ }^{58}$ given that this represents possibly the best currently available, if computationally expensive, method the agreement is gratifying. The agreement with the PI-N hindered rotor treatment ${ }^{35}$ due to Gao et al. is far less satisfactory. As regards the isobaric heat capacity, $C_{p}^{\ominus}(300 \mathrm{~K})$, the agreement is not as good but our result of $74.5 \mathrm{~J} \mathrm{~K}^{-1} \mathrm{~mol}^{-1}$ is bracketed by the literature $74.0-79.5 \mathrm{~J} \mathrm{~K}^{-1} \mathrm{~mol}^{-1}$ — the agreement improves significantly at the higher temperatures. Note that subsequent 
Table 15: $\mathrm{H}_{3} \mathrm{COC}^{\bullet}(\mathrm{O})_{2}: C_{p}^{\ominus} / \mathrm{J} \mathrm{K}^{-1} \mathrm{~mol}^{-1}$

\begin{tabular}{ccccccc}
\hline$T / \mathrm{K}$ & B3LYP & BMK & $\omega$ B97X-D & MN12-L & $\left\langle C_{p}^{\ominus}\right\rangle$ & $\sigma$ \\
\hline 298.15 & 74.25 & 74.39 & 76.07 & 73.45 & 74.54 & 1.10 \\
300 & 74.53 & 74.66 & 76.32 & 73.72 & 74.81 & 1.09 \\
400 & 89.52 & 89.42 & 90.21 & 88.41 & 89.39 & 0.74 \\
500 & 103.15 & 103.20 & 103.29 & 101.98 & 102.91 & 0.62 \\
600 & 114.50 & 115.06 & 114.54 & 113.55 & 114.41 & 0.63 \\
700 & 123.68 & 124.87 & 123.89 & 123.14 & 123.90 & 0.72 \\
800 & 131.08 & 132.79 & 131.6 & 131.03 & 131.63 & 0.82 \\
900 & 137.11 & 139.10 & 137.98 & 137.55 & 137.94 & 0.85 \\
1000 & 142.08 & 144.10 & 143.27 & 142.97 & 143.11 & 0.83 \\
1100 & 146.22 & 148.06 & 147.71 & 147.49 & 147.37 & 0.80 \\
1200 & 149.70 & 151.23 & 151.46 & 151.32 & 150.93 & 0.82 \\
1300 & 152.65 & 153.79 & 154.66 & 154.57 & 153.92 & 0.93 \\
1400 & 155.19 & 155.88 & 157.42 & 157.37 & 156.47 & 1.11 \\
1500 & 157.37 & 157.62 & 159.82 & 159.80 & 158.65 & 1.34 \\
1600 & 159.27 & 159.07 & 161.92 & 161.92 & 160.55 & 1.59 \\
1800 & 162.39 & 161.37 & 165.4 & 165.43 & 163.65 & 2.08 \\
2000 & 164.84 & 163.06 & 168.13 & 168.20 & 166.06 & 2.54 \\
\hline \hline
\end{tabular}

Table 16: $\mathrm{H}_{3} \mathrm{COC}^{\bullet}(\mathrm{O})_{2}:\left(H_{T}^{\ominus}-H_{0}^{\ominus}\right) / \mathrm{kJ} \mathrm{mol}^{-1}$

\begin{tabular}{ccccccc}
\hline$T / \mathrm{K}$ & B3LYP & BMK & $\omega$ B97X-D & MN12-L & $\left\langle\left(H_{T}^{\ominus}-H_{0}^{\ominus}\right)\right\rangle$ & $\sigma$ \\
\hline 298.15 & 16.22 & 16.25 & 16.83 & 15.98 & 16.32 & 0.36 \\
300 & 16.36 & 16.39 & 16.97 & 16.12 & 16.46 & 0.36 \\
400 & 24.56 & 24.60 & 25.29 & 24.22 & 24.67 & 0.45 \\
500 & 34.21 & 34.24 & 34.98 & 33.76 & 34.30 & 0.51 \\
600 & 45.11 & 45.17 & 45.89 & 44.55 & 45.18 & 0.55 \\
700 & 57.04 & 57.18 & 57.82 & 56.40 & 57.11 & 0.58 \\
800 & 69.79 & 70.08 & 70.61 & 69.12 & 69.90 & 0.62 \\
900 & 83.20 & 83.68 & 84.10 & 82.56 & 83.39 & 0.66 \\
1000 & 97.17 & 97.85 & 98.17 & 96.59 & 97.45 & 0.71 \\
1100 & 111.59 & 112.46 & 112.72 & 111.12 & 111.97 & 0.75 \\
1200 & 126.39 & 127.43 & 127.68 & 126.06 & 126.89 & 0.79 \\
1300 & 141.51 & 142.69 & 142.99 & 141.36 & 142.14 & 0.82 \\
1400 & 156.90 & 158.17 & 158.60 & 156.96 & 157.66 & 0.86 \\
1500 & 172.53 & 173.85 & 174.46 & 172.82 & 173.42 & 0.90 \\
1600 & 188.36 & 189.68 & 190.55 & 188.91 & 189.38 & 0.95 \\
1800 & 220.54 & 221.74 & 223.29 & 221.65 & 221.81 & 1.13 \\
2000 & 253.27 & 254.18 & 256.65 & 255.02 & 254.78 & 1.44 \\
\hline \hline
\end{tabular}


simulation work ${ }^{46}$ has used the thermodata results of Sun et al. ${ }^{47}$

Table 17: $S^{\ominus}(298.15 \mathrm{~K})$ and $C_{p}^{\ominus}: / \mathrm{J} \mathrm{K}^{-1} \mathrm{~mol}^{-1}$

\begin{tabular}{llll}
\hline \multicolumn{1}{c}{$S^{\ominus}$} & $C_{p}^{\ominus}(300 \mathrm{~K})$ & $C_{p}^{\ominus}(1,500 \mathrm{~K})$ & Method \\
\hline 296.4 & 74.94 & 157.9 & B3LYP/6-31G(d,p) ${ }^{45}$ \\
300.6 & 79.54 & 155.4 & M06-2X/cc-pVTZ ${ }^{47}$ \\
311.3 & 77.70 & 158.9 & MN12-L/ma-TZVP; MS-T ${ }^{36,52}$ \\
317.6 & 74.01 & 156.6 & MN12-L/ma-TZVP; PI-N \\
$311.2 \pm 1.6$ & $74.54 \pm 1.10$ & $158.7 \pm 1.3$ & This work \\
\hline \hline
\end{tabular}

\section{Summary}

This is a difficult species to study ${ }^{43}$ but the density functionals employed here at least do not give rise to un-physical and anomalous frequencies. However VPT2 calculations indicate that the M06-2X functional does give to much larger anharmonicity coefficients than expected and hence is not really suitable in cases like these. Calculations show that its entropy and its heat capacity are both outliers with only the enthalpy function within the fold and so the M06-2X functional results are disregarded and replaced by BMK with the following recommendations applying: $S^{\ominus}=311.2 \pm 1.6, C_{p}^{\ominus}=74.54 \pm 1.10 \mathrm{~J} \mathrm{~K}^{-1} \mathrm{~mol}^{-1}$ and $\left(H_{T}^{\ominus}-H_{0}^{\ominus}\right)=16.32 \pm 0.36$ $\mathrm{kJ} \mathrm{mol}{ }^{-1}$ at $298.15 \mathrm{~K}$.

\section{Case study IV: $\mathrm{CH}_{3} \mathrm{CH}_{2} \mathrm{CH}_{2} \mathrm{OO}^{\circ}$}

n-Propyldioxy or the n-propyl peroxy radical is a key intermediate in the oxidation of propane and has thus been subject of many studies. ${ }^{59-64}$ Cavity ringdown experiments backed up by electronic structure calculation pinpoint the G1G2 conformer (naming the $\angle$ OOCC first and the $\angle \mathrm{OCCC}$ second; the third dihedral $\angle \mathrm{HCCC}$ is almost always ignored or is less relevant) as the ground state. ${ }^{65-67}$ Wang and Bozzelli ${ }^{61}$ carried out the most detailed computation of thermochemical parameters from B3LYP/6-31G(d) frequencies, scaled by 0.964, and relaxed potential scans. 


\section{Frequencies}

Geometry optimisations and frequencies reveal a ${ }^{2} A$ ground state of symmetry $C_{1}$ and diagnostic $T_{1}=0.0176$ for the 'optically active' gauche/gauche conformer (B3LYP: $\angle \mathrm{OOCC}$ $-72.87^{\circ}$ and $\left.\angle \mathrm{OCCC}-63.34^{\circ}\right)$. Hoobler et al. investigated the ground-state rotamers ${ }^{62}$ using high-level methods (their G1G2 $\angle \mathrm{OOCC}-71.23^{\circ}$ and $\angle \mathrm{OCCC}-61.41^{\circ}$ ) and determined anharmonic frequencies at $\mathrm{UHF}-\mathrm{CCSD}(\mathrm{T}) / \mathrm{ANO} 0$. Their frequencies are in very good accord with the averaged values computed from the four functionals, Table 18, with differences rarely exceeding $1 \%$; where there is a large difference — of $7 \%$ - it can be readily explained as inconsequential, viz. $\bar{\nu}_{30}$, which will be treated as a hindered rotor.

\section{Hindered rotors}

Taczay and colleagues ${ }^{67}$ computed barriers to rotation between each conformer at B3LYP/6$31+\mathrm{G}^{*}$ and showed that the maximum height was of the order of $1,000 \mathrm{~cm}^{-1}$ or $\sim 12 \mathrm{~kJ}$ $\mathrm{mol}^{-1}$. Comparable results were obtained here, Figure 2, for well-behaved scans at all four functionals tested. The three-fold symmetric methyl rotors (not shown in Fig. 2) all have barriers of $\sim 11 \mathrm{~kJ} \mathrm{~mol}^{-1}$.

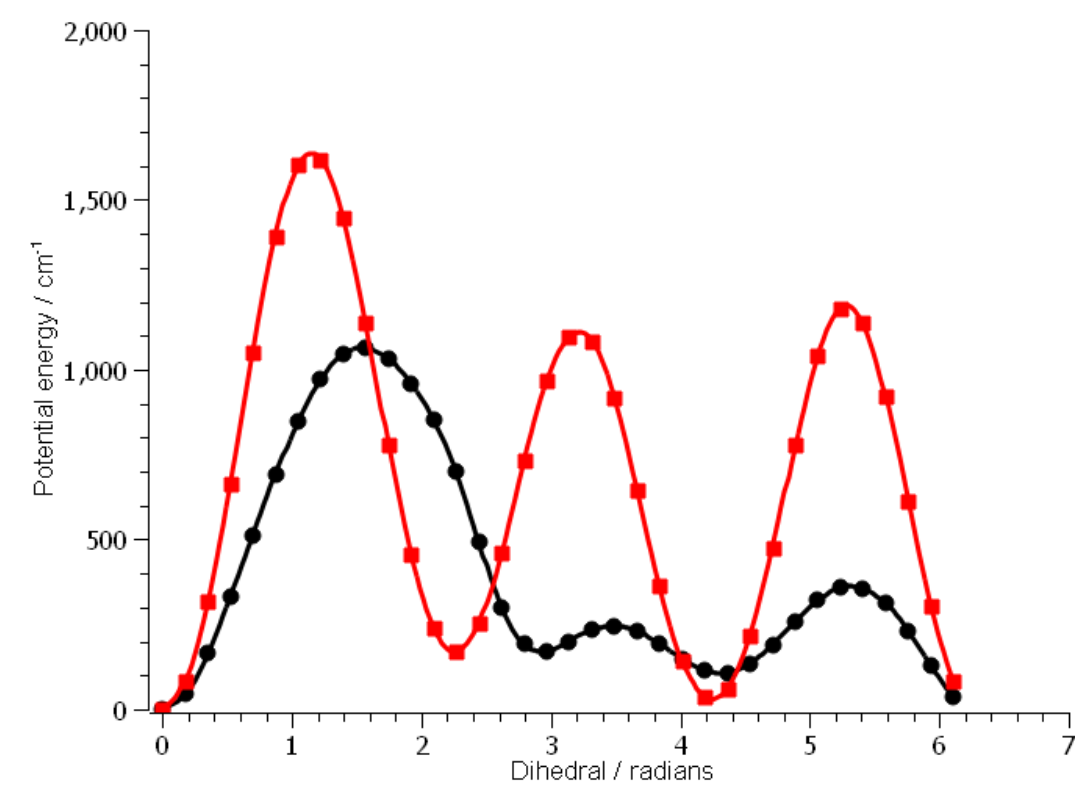

Figure 2: Scans at B2PLYP/cc-pVTZ+d: $\angle \mathrm{CCCO}-, \angle \mathrm{CCOO}-$ 
Table 18: n-Propyldioxy; frequencies and anharmonicity coefficients at cc-pVTZ $+\mathrm{d} / \mathrm{cm}^{-1}$

\begin{tabular}{|c|c|c|c|c|c|c|c|c|c|c|}
\hline \multicolumn{2}{|c|}{ B3LYP } & \multicolumn{2}{|c|}{$\omega B 97 X-D$} & \multicolumn{2}{|c|}{ MN12-L } & \multicolumn{2}{|c|}{ B2PLYP } & \multicolumn{2}{|c|}{ Means } & \multirow{2}{*}{$\begin{array}{c}\mathrm{CCSD}(\mathrm{T}) \\
\bar{\nu}\end{array}$} \\
\hline $\bar{\nu}$ & $x_{i i}$ & $\bar{\nu}$ & $x_{i i}$ & $\bar{\nu}$ & $x_{i i}$ & $\bar{\nu}$ & $x_{i i}$ & $\langle\bar{\nu}\rangle$ & $\sigma$ & \\
\hline 3112.46 & -30.97 & 3139.12 & -26.88 & 3138.52 & -30.45 & 3146.85 & -30.69 & 3134.24 & 15.00 & 3148 \\
\hline 3103.54 & -30.64 & 3135.96 & -27.38 & 3125.41 & -17.03 & 3136.22 & -29.77 & 3125.28 & 15.34 & 3144 \\
\hline 3092.29 & -19.65 & 3125.14 & -15.81 & 3112.76 & -24.51 & 3125.28 & -18.67 & 3113.87 & 15.54 & 3132 \\
\hline 3067.42 & -17.66 & 3101.54 & -18.60 & 3091.96 & -19.30 & 3101.55 & -20.52 & 3090.62 & 16.11 & 3108 \\
\hline 3053.20 & -22.25 & 3076.89 & -23.44 & 3040.59 & -18.26 & 3082.58 & -25.08 & 3063.31 & 19.78 & 3077 \\
\hline 3030.96 & -16.37 & 3060.39 & -27.96 & 3034.73 & -19.07 & 3058.59 & -34.62 & 3046.17 & 15.48 & 3055 \\
\hline 3029.27 & -25.68 & 3050.69 & -18.29 & 3025.88 & -17.17 & 3055.07 & -19.14 & 3040.23 & 14.78 & 3048 \\
\hline 1508.08 & -3.47 & 1512.73 & -2.92 & 1520.15 & -3.54 & 1520.74 & -3.27 & 1515.42 & 6.10 & 1514 \\
\hline 1502.77 & -4.43 & 1508.52 & -1.61 & 1515.05 & -2.28 & 1515.53 & -2.33 & 1510.47 & 6.05 & 1508 \\
\hline 1482.23 & -3.37 & 1489.31 & -4.95 & 1491.28 & -4.58 & 1493.20 & -2.46 & 1489.00 & 4.79 & 1486 \\
\hline 1480.26 & -2.75 & 1488.6 & -5.94 & 1487.46 & -1.22 & 1492.38 & -5.83 & 1487.17 & 5.07 & 1484 \\
\hline 1421.91 & -9.77 & 1429.69 & -1.16 & 1429.75 & -1.45 & 1429.84 & -1.49 & 1427.80 & 3.92 & 1423 \\
\hline 1384.54 & -7.08 & 1404.47 & -7.15 & 1400.86 & -7.74 & 1397.12 & -7.04 & 1396.75 & 8.67 & 1396 \\
\hline 1377.75 & -3.80 & 1383.55 & -3.71 & 1382.52 & -4.44 & 1384.09 & -3.62 & 1381.98 & 2.89 & 1374 \\
\hline 1300.15 & -2.09 & 1312.02 & -2.59 & 1317.77 & -2.65 & 1308.80 & -2.12 & 1309.69 & 7.36 & 1302 \\
\hline 1285.74 & -1.71 & 1307.89 & -1.83 & 1310.98 & -1.27 & 1295.46 & -1.75 & 1300.02 & 11.64 & 1281 \\
\hline 1190.21 & -1.47 & 1241.39 & -3.58 & 1208.04 & -2.74 & 1205.68 & -1.79 & 1211.33 & 21.54 & 1187 \\
\hline 1148.64 & -3.45 & 1183.08 & -1.25 & 1183.18 & -2.12 & 1168.89 & -1.98 & 1170.95 & 16.32 & 1115 \\
\hline 1106.35 & -1.65 & 1118.3 & -1.73 & 1122.09 & -1.87 & 1116.24 & -1.81 & 1115.75 & 6.72 & 1096 \\
\hline 1045.63 & -2.84 & 1065.21 & -2.47 & 1062.54 & -2.40 & 1058.29 & -2.39 & 1057.92 & 8.67 & 1051 \\
\hline 941.08 & 0.02 & 959.11 & -0.49 & 961.80 & -1.58 & 948.57 & -0.05 & 952.64 & 9.59 & 947 \\
\hline 880.28 & -1.40 & 903.69 & -0.74 & 907.63 & -0.01 & 893.58 & -1.12 & 896.30 & 12.21 & 895 \\
\hline 853.54 & -1.35 & 873.69 & -1.35 & 881.8 & -1.40 & 865.06 & -1.35 & 868.52 & 12.10 & 863 \\
\hline 755.74 & 1.63 & 768.54 & 2.96 & 766.7 & 4.34 & 762.70 & 1.85 & 763.42 & 5.67 & 757 \\
\hline 542.92 & -1.07 & 560.8 & -0.29 & 562.51 & -0.09 & 545.66 & -0.86 & 552.97 & 10.11 & 543 \\
\hline 429.60 & -0.88 & 437.55 & -1.54 & 423.41 & -1.65 & 432.12 & -1.59 & 430.67 & 5.87 & 431 \\
\hline 289.22 & -0.72 & 295.41 & -0.39 & 291.03 & -0.59 & 291.20 & -0.73 & 291.71 & 2.62 & 290 \\
\hline 219.28 & -2.67 & 226.67 & -2.71 & 238.12 & -5.44 & 223.32 & -1.49 & 226.85 & 8.10 & 226 \\
\hline 139.71 & -3.30 & 148.23 & 0.77 & 169.62 & -4.94 & 144.19 & -1.28 & 150.44 & 13.25 & 153 \\
\hline 78.32 & -0.31 & 77.69 & 0.93 & 66.55 & -4.54 & 78.21 & 0.38 & 75.19 & 5.77 & 81 \\
\hline
\end{tabular}




\section{Entropy and isobaric heat capacity}

A complete treatment is employed here, anharmonic frequencies and hindered rotors with excellent consistent results, Tables 19-21, over the whole temperature range. The very small uncertainty changes little with increasing temperature and in the case of the heat capacity remains small and constant.

Table 19: n-Propyldioxy: variation of $S^{\ominus} / \mathrm{J} \mathrm{K}^{-1} \mathrm{~mol}^{-1}$

\begin{tabular}{ccccccc}
\hline$T / \mathrm{K}$ & B3LYP & wB97X-D & MN12-L & B2PLYP & $\left\langle S^{\ominus}\right\rangle$ & $\sigma$ \\
\hline 298.15 & 356.81 & 355.35 & 355.04 & 356.06 & 355.82 & 0.79 \\
300 & 357.40 & 355.94 & 355.64 & 356.65 & 356.41 & 0.79 \\
400 & 388.10 & 386.32 & 386.37 & 387.16 & 386.99 & 0.84 \\
500 & 416.63 & 414.54 & 414.74 & 415.53 & 415.36 & 0.95 \\
600 & 443.30 & 440.94 & 441.20 & 442.07 & 441.88 & 1.06 \\
700 & 468.24 & 465.64 & 465.94 & 466.90 & 466.68 & 1.17 \\
800 & 491.59 & 488.81 & 489.13 & 490.17 & 489.93 & 1.25 \\
900 & 513.52 & 510.57 & 510.90 & 512.02 & 511.75 & 1.33 \\
1000 & 534.16 & 531.07 & 531.41 & 532.59 & 532.31 & 1.40 \\
1100 & 553.64 & 550.42 & 550.78 & 552.01 & 551.71 & 1.45 \\
1200 & 572.06 & 568.74 & 569.10 & 570.37 & 570.07 & 1.50 \\
1300 & 589.52 & 586.10 & 586.47 & 587.79 & 587.47 & 1.55 \\
1400 & 606.11 & 602.59 & 602.97 & 604.33 & 604.00 & 1.59 \\
1500 & 621.88 & 618.29 & 618.67 & 620.06 & 619.73 & 1.63 \\
1600 & 636.92 & 633.25 & 633.64 & 635.06 & 634.72 & 1.66 \\
1800 & 665.00 & 661.20 & 661.60 & 663.09 & 662.72 & 1.72 \\
2000 & 690.76 & 686.84 & 687.25 & 688.79 & 688.41 & 1.78 \\
\hline \hline
\end{tabular}

\section{Enthalpy function}

There is only one value of $18.723 \mathrm{~kJ} \mathrm{~mol}^{-1}$ extant in the literature ${ }^{37}$ which is not in good agreement with this work, Table 21.

\section{Comparison with literature}

It is unclear whether earlier values ${ }^{4,37,68,69}$ for the entropy included a correction of $\mathrm{R} \ln (2)=$ $5.76 \mathrm{~J} \mathrm{~K}^{-1} \mathrm{~mol}^{-1}$, to allow for 'optical isomers' if so that might account for the entropy differences but Wang and Bozzelli ${ }^{61}$ do include it. 
Table 20: n-Propyldioxy: variation of $C_{p}^{\ominus} / \mathrm{J} \mathrm{K}^{-1} \mathrm{~mol}^{-1}$

\begin{tabular}{ccccccc}
\hline$T / \mathrm{K}$ & B3LYP & $\omega$ B97X-D & MN12-L & B2PLYP & $\left\langle C_{p}^{\ominus}\right\rangle$ & $\sigma$ \\
\hline 298.15 & 95.79 & 95.02 & 96.62 & 95.22 & 95.66 & 0.72 \\
300 & 96.20 & 95.41 & 96.99 & 95.63 & 96.06 & 0.71 \\
400 & 118.12 & 116.78 & 117.68 & 117.41 & 117.50 & 0.56 \\
500 & 137.89 & 136.40 & 136.90 & 137.19 & 137.10 & 0.62 \\
600 & 154.66 & 153.17 & 153.45 & 153.98 & 153.82 & 0.66 \\
700 & 168.83 & 167.37 & 167.54 & 168.15 & 167.97 & 0.66 \\
800 & 180.93 & 179.52 & 179.64 & 180.26 & 180.09 & 0.65 \\
900 & 191.37 & 189.99 & 190.10 & 190.70 & 190.54 & 0.64 \\
1000 & 200.41 & 199.08 & 199.18 & 199.75 & 199.61 & 0.61 \\
1100 & 208.28 & 206.99 & 207.09 & 207.63 & 207.50 & 0.59 \\
1200 & 215.14 & 213.89 & 213.98 & 214.51 & 214.38 & 0.58 \\
1300 & 221.12 & 219.91 & 220.00 & 220.51 & 220.39 & 0.56 \\
1400 & 226.36 & 225.17 & 225.27 & 225.77 & 225.64 & 0.55 \\
1500 & 230.95 & 229.79 & 229.89 & 230.39 & 230.26 & 0.53 \\
1600 & 234.99 & 233.85 & 233.95 & 234.46 & 234.31 & 0.52 \\
1800 & 241.72 & 240.62 & 240.72 & 241.24 & 241.08 & 0.51 \\
2000 & 247.04 & 245.96 & 246.06 & 246.61 & 246.42 & 0.50 \\
\hline \hline
\end{tabular}

Table 21: n-Propyldioxy: variation of $\left(H_{T}^{\ominus}-H_{0}^{\ominus}\right) / \mathrm{kJ} \mathrm{mol}^{-1}$

\begin{tabular}{ccccccc}
\hline$T / \mathrm{K}$ & B3LYP & $\omega$ B97X-D & MN12-L & B2PLYP & $\left\langle\left(H_{T}^{\ominus}-H_{0}^{\ominus}\right)\right\rangle$ & $\sigma$ \\
\hline 298.15 & 20.09 & 20.36 & 20.73 & 20.21 & 20.35 & 0.28 \\
300 & 20.26 & 20.54 & 20.91 & 20.38 & 20.52 & 0.28 \\
400 & 30.99 & 31.15 & 31.64 & 31.04 & 31.21 & 0.30 \\
500 & 43.81 & 43.83 & 44.39 & 43.79 & 43.96 & 0.29 \\
600 & 58.46 & 58.33 & 58.93 & 58.37 & 58.52 & 0.28 \\
700 & 74.65 & 74.38 & 74.99 & 74.50 & 74.63 & 0.26 \\
800 & 92.15 & 91.73 & 92.36 & 91.93 & 92.04 & 0.27 \\
900 & 110.78 & 110.22 & 110.86 & 110.49 & 110.59 & 0.29 \\
1000 & 130.38 & 129.68 & 130.33 & 130.02 & 130.10 & 0.32 \\
1100 & 150.82 & 149.99 & 150.65 & 150.40 & 150.47 & 0.36 \\
1200 & 172.00 & 171.04 & 171.71 & 171.51 & 171.57 & 0.40 \\
1300 & 193.81 & 192.74 & 193.42 & 193.27 & 193.31 & 0.44 \\
1400 & 216.19 & 214.99 & 215.68 & 215.58 & 215.61 & 0.49 \\
1500 & 239.06 & 237.75 & 238.44 & 238.39 & 238.41 & 0.54 \\
1600 & 262.36 & 260.93 & 261.64 & 261.64 & 261.64 & 0.58 \\
1800 & 310.05 & 308.40 & 309.13 & 309.23 & 309.20 & 0.68 \\
2000 & 358.94 & 357.07 & 357.82 & 358.03 & 357.97 & 0.77 \\
\hline \hline
\end{tabular}


Table $22: S^{\ominus}(298.15 \mathrm{~K})$ and $C_{p}^{\ominus}: / \mathrm{J} \mathrm{K}^{-1} \mathrm{~mol}^{-1}$

\begin{tabular}{llll}
\hline \multicolumn{1}{c}{$S^{\ominus}$} & $C_{p}^{\ominus}(300 \mathrm{~K})$ & $C_{p}^{\ominus}(1,500 \mathrm{~K})$ & Method \\
\hline 346.4 & 112.8 & & B3LYP $/ 6-311 \mathrm{G}(\mathrm{d}, \mathrm{p})^{68}$ \\
$349.4 \pm 7.1$ & $96.23 \pm 6.3$ & $228.9 \pm 5.9$ & B3LYP $/ 6-311+\mathrm{G}(\mathrm{d}, \mathrm{p})^{4}$ \\
324.8 & 90.42 & & B3LYP/6-31G(d) \\
340.2 & & & Review 69 \\
360.6 & 94.10 & 227.9 & B3LYP/6-31+G(d,p) ${ }^{61}$ \\
$355.8 \pm 0.8$ & $95.66 \pm 0.72$ & $230.3 \pm 0.5$ & This work \\
\hline \hline
\end{tabular}

\section{Is there a basis set dependence?}

Apart from demonstrating that the barrier to a relaxed potential energy scan shows little dependence on basis set used, Table 2, so far the impact on computed thermochemical parameters has not been shown. Testing for this proposition has been done for the M06-2X functional with a complete anharmonic hindered rotor treatment including scans at the same level and the results are clear-cut, Table 23, showing very little dependence on chosen basis set with the variance not even reaching $1 \%$. The heat capacity is more sensitive at the lower temperatures but this rapidly diminishes and is absent by $500 \mathrm{~K}$.

A comprehensive study on the accuracy of basis sets for anharmonic molecular vibrations of a small set of closed-shell molecules by Mitra and Roy ${ }^{70}$ showed that $6-311 G(d)$ is a good compromise between accuracy and computational cost; however, their work focussed on high-frequency $\mathrm{O}-\mathrm{H}, \mathrm{C}=\mathrm{O}, \mathrm{C}-\mathrm{O}$ and $\mathrm{C}-\mathrm{H}$ stretches which have minimal impact on entropy calculations.

Lee and McCarthy ${ }^{71}$ carried out a Bayesian analysis of theoretical rotational constants and showed that B3LYP and MP2 yielded lower accuracy and higher uncertainty than the Minnesota family and $\omega$ B97X-D; however the differences are barely significant when, as here, a triple- $\zeta$ quality basis set is used and in addition the impact on the entropy of rotational constant variability, is trivial (sample variance of $<0.02$ ). 
Table 23: M06-2X results for entropy, heat capacity and enthalpy function

\begin{tabular}{|c|c|c|c|c|}
\hline$T / \mathrm{K}$ & $6-31 G(d)$ & $6-311++\mathrm{G}(\mathrm{d}, \mathrm{p})$ & cc-pVTZ+d & def2QZVpp \\
\hline \multicolumn{5}{|c|}{$S^{\ominus} / \mathrm{J} \mathrm{K}^{-1} \mathrm{~mol}^{-1}$} \\
\hline 298.15 & 354.59 & 355.16 & 355.17 & 355.42 \\
\hline 500 & 414.08 & 414.29 & 414.45 & 414.36 \\
\hline 1,500 & 617.81 & 618.09 & 618.37 & 617.07 \\
\hline \multicolumn{5}{|c|}{$C_{p}^{\ominus} / \mathrm{J} \mathrm{K}^{-1} \mathrm{~mol}^{-1}$} \\
\hline 298.15 & 96.13 & 94.85 & 95.29 & 94.57 \\
\hline 500 & 136.58 & 136.38 & 136.53 & 135.87 \\
\hline 1,500 & 230.12 & 229.97 & 230.22 & 228.44 \\
\hline \multicolumn{5}{|c|}{$\left(H_{T}^{\ominus}-H_{0}^{\ominus}\right) / \mathrm{kJ} \mathrm{mol}^{-1}$} \\
\hline 298.15 & 20.67 & 20.48 & 20.54 & 20.31 \\
\hline 500 & 44.24 & 43.93 & 44.04 & 43.68 \\
\hline 1,500 & 238.15 & 237.90 & 238.14 & 236.57 \\
\hline
\end{tabular}

\section{Summary}

This molecule is not particularly challenging but does provide a good test of the methodology to be employed in that there is a clear difference between a HO-RR approach and more elaborate treatments, but advanced, computationally demanding, methods are not required. Note that additional functionals, such as M06-2X and BMK, give rise to values which are in very good agreement with the values determined by the 'training set', namely B3LYP, $\omega$ B97X-D, MN12-L and B2PLYP. Although not tabulated here both M06-2X/cc-pVTZ+d and BMK/cc-pVTZ $+\mathrm{d}$ results are in complete agreement with the averaged values, viz. $S^{\ominus}(298.15 \mathrm{~K})=355.17$ and $355.55, C_{p}^{\ominus}(298.15 \mathrm{~K})=95.29$ and 94.34 , both in $\mathrm{J} \mathrm{K}^{-1} \mathrm{~mol}^{-1}$, and $\left(H_{298.15}^{\ominus}-H_{0}^{\ominus}\right)=20.54$ and $20.21 \mathrm{~kJ} \mathrm{~mol}^{-1}$, respectively.

\section{Case study V: $\mathrm{H}_{3} \mathrm{CCH}=\mathrm{CHCH}_{2} \mathrm{OH}$}

But-2-en-1-ol or crotyl alcohol is one of the species considered by Ghahremanpour et al. in large scale calculations of gas-phase thermochemistry, using composite methods CBS-QB3 ${ }^{72}$ and $\mathrm{Gn}^{73}$ to compute the entropy and heat capacity. ${ }^{74}$ Here we consider the E-conformer in its skew form, Fig. 3, as outlined by Caminati et al. from high resolution microwave studies of trans-crotyl alcohol. ? 


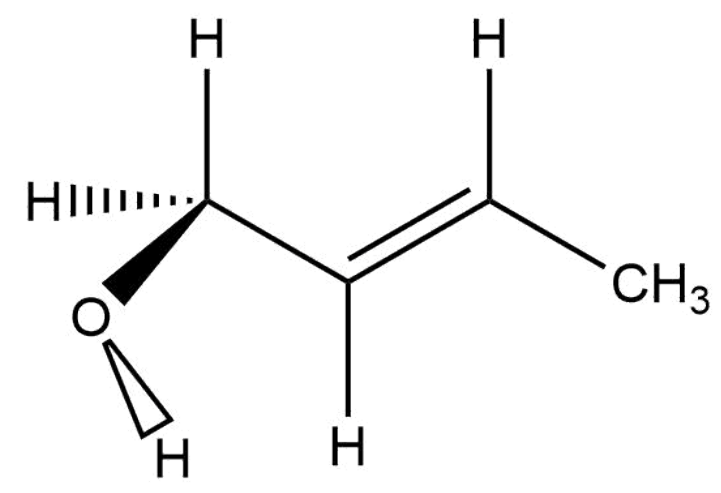

Figure 3: Trans-Crotyl alcohol

\section{Frequencies}

A consistent set of frequencies is obtained, Table 24, but the anharmonic coefficients show that M06-2X is an outlier particularly for modes \# 29, 31 and 33 which correspond to hindered rotors.

\section{Hindered rotors}

Three clearly defined hindered rotors are present (1) methyl with barriers of $\sim 8 \mathrm{~kJ} \mathrm{~mol}^{-1}$, (2) $\mathrm{CH}_{2} \mathrm{OH}$ and (3) OH. Eleven out of twelve relaxed potential energy scans are well-behaved except for an M06-2X/cc-pVTZ+d scan about the HCCO dihedral, Fig. 4. In this scan as the alcoholic H-atom nears an ethenic hydrogen, Fig. 5b, the minimisation algorithm suddenly switches and disrupts the smooth continuous scan - the other functionals show much less disruption and therefore acceptable scans. Note also the large change in the HOCC angle in the sequence, Fig. 5 .

The presumption is that this is due to the parametrisation of the M06-2X functional and in this particular instance changing the basis set to $6-311++\mathrm{G}(\mathrm{d}$,) ensures satisfactory curve. 
Table 24: Crotyl alcohol: frequencies and anharmonicities $/ \mathrm{cm}^{-1}$

\begin{tabular}{|c|c|c|c|c|c|c|c|c|c|c|}
\hline & \multicolumn{2}{|c|}{ B3LYP } & \multicolumn{2}{|c|}{ M06-2X } & \multicolumn{2}{|c|}{$\omega \mathrm{B} 97 \mathrm{XD}$} & \multicolumn{2}{|c|}{ B2PLYP } & \multicolumn{2}{|c|}{ Means } \\
\hline$\#$ & $\bar{\nu}$ & $x_{i i}$ & $\bar{\nu}$ & $x_{i i}$ & $\bar{\nu}$ & $x_{i i}$ & 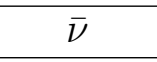 & $x_{i i}$ & $\langle\bar{\nu}\rangle$ & $\sigma$ \\
\hline 1 & 05. & 64 & 76. & 27 & 5. & 50 & 29.27 & 929 & 51.66 & 1.47 \\
\hline 2 & & & & & & & & & & \\
\hline 3 & & & & 2 & & & & & & \\
\hline 4 & & & & & & & 92 & & & \\
\hline 5 & & & & & & & 3.23 & & & \\
\hline 6 & & & & & & & 2.55 & & & \\
\hline 7 & & & & & & & .99 & & & \\
\hline 8 & & & & & & & 0.85 & & & \\
\hline 9 & 1.34 & & & & & & .07 & & .92 & 21.67 \\
\hline 10 & 5.79 & & & -4 . & & & .65 & & 64 & 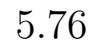 \\
\hline 11 & .92 & & & & & & & & & \\
\hline 12 & & & & & & & & & & \\
\hline 13 & & & & & & & & & & \\
\hline 12 & & & & & & & & & & \\
\hline 1 & & & & & & & & & & \\
\hline 16 & & & & & & & & & & \\
\hline 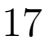 & & & & & & & & & & \\
\hline 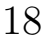 & & & & & & & & & & \\
\hline 1 & & & & & & & & & 24 & \\
\hline 20 & & & & & & & & & 76 & 15.13 \\
\hline 2 & & & & & & & & & & \\
\hline 2 & & & & & & & & & & 22.43 \\
\hline 2 & & & & & & & & & & \\
\hline 2 & & & & & & & & & & \\
\hline 2 & & & & & & & & & & \\
\hline ? & & & & & & & & & & \\
\hline ? & & & & & & & & & & \\
\hline ? & & & & & & & & & & \\
\hline 2 & & & & & & & & & & \\
\hline 3 & & & & & & & & & & \\
\hline 3 & & & & & & & & & & \\
\hline (2) & & & & & & & & & & \\
\hline & & & 57 & & 99.21 & & 77 & 7 & .73 & 57 \\
\hline
\end{tabular}




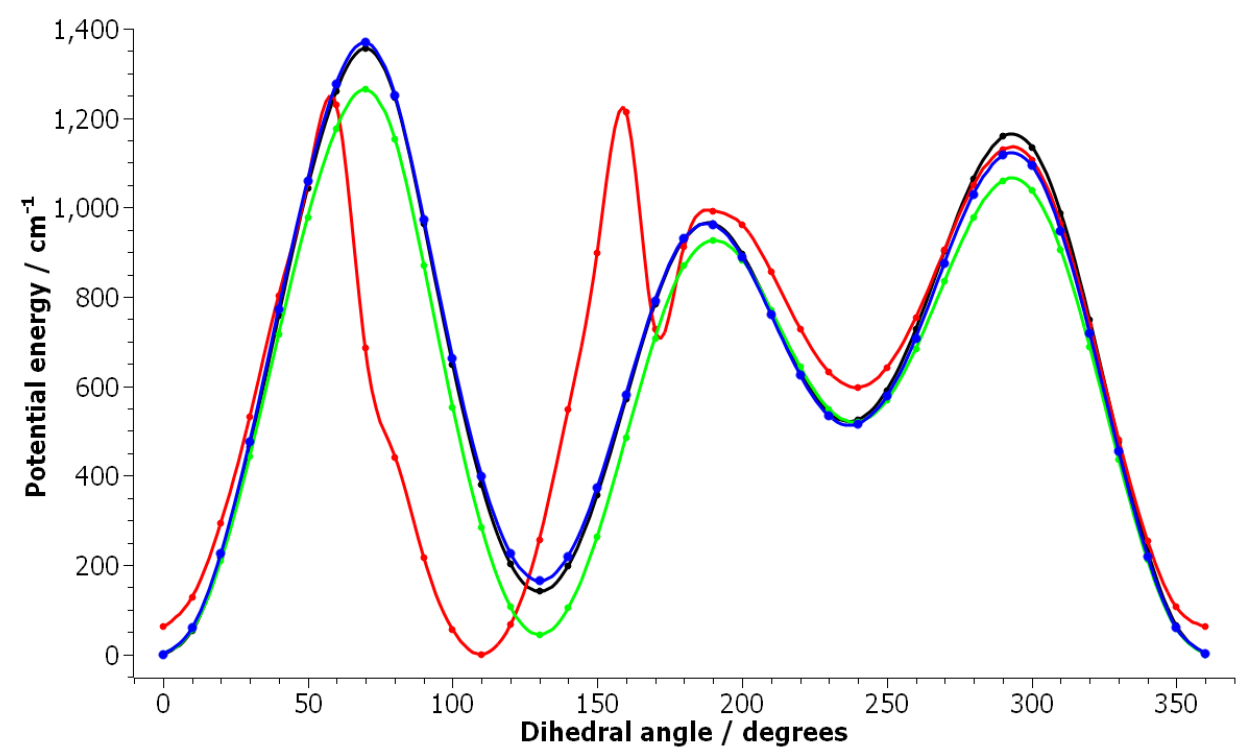

Figure 4: Scans; B2PLYP —, M06-2X —, wB97XD —, B3LYP -

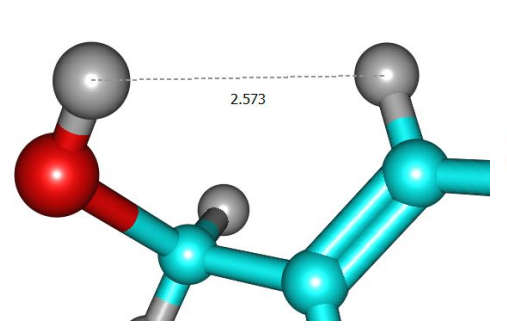

(a) $\angle-128^{\circ}$

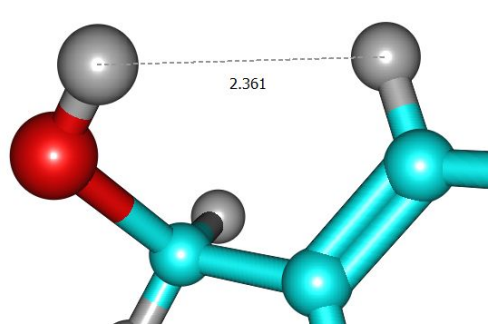

(b) $\angle-118^{\circ}$

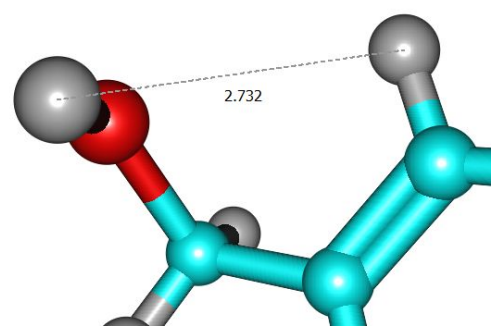

(c) $\angle-108^{\circ}$

Figure 5: $\mathrm{H}-\mathrm{H}$ interactions during relaxed scan of OCCC dihedral 


\section{Entropy and heat capacity}

Consistent results are obtained for all four functionals, Table 25; the full treatment shows an increase in $S^{\ominus}(298.15 \mathrm{~K})$ of $14 \mathrm{~J} \mathrm{~K}^{-1} \mathrm{~mol}^{-1}$ over a purely vibrational one. The failed M06-2X/cc-pVTZ $+\mathrm{d}$ scan of $\angle \mathrm{OCCC}$ being replaced by one at M06-2X/6-311++G(d,p).

Table 25: Crotyl alcohol: entropy / $\mathrm{J} \mathrm{K}^{-1} \mathrm{~mol}^{-1}$

\begin{tabular}{ccccccc}
\hline$T / \mathrm{K}$ & B3LYP & M06-2X & $\omega$ B97X-D & B2PLYP & $\left\langle S^{\ominus}\right\rangle$ & $\sigma$ \\
\hline 298.15 & 345.68 & 344.94 & 345.26 & 345.31 & 345.30 & 0.30 \\
300 & 346.37 & 345.63 & 345.95 & 346.01 & 345.99 & 0.30 \\
400 & 381.30 & 380.37 & 380.39 & 380.84 & 380.73 & 0.44 \\
500 & 412.67 & 411.63 & 411.43 & 412.14 & 411.97 & 0.56 \\
600 & 441.54 & 440.4 & 440.04 & 440.95 & 440.73 & 0.66 \\
700 & 468.38 & 467.13 & 466.64 & 467.72 & 467.47 & 0.75 \\
800 & 493.47 & 492.14 & 491.53 & 492.75 & 492.47 & 0.83 \\
900 & 517.04 & 515.63 & 514.91 & 516.27 & 515.96 & 0.91 \\
1000 & 539.25 & 537.78 & 536.96 & 538.43 & 538.11 & 0.97 \\
1100 & 560.25 & 558.73 & 557.80 & 559.38 & 559.04 & 1.03 \\
1200 & 580.14 & 578.58 & 577.54 & 579.24 & 578.88 & 1.10 \\
1300 & 599.03 & 597.45 & 596.30 & 598.11 & 597.72 & 1.15 \\
1400 & 617.01 & 615.4 & 614.14 & 616.06 & 615.65 & 1.21 \\
1500 & 634.14 & 632.51 & 631.14 & 633.18 & 632.74 & 1.26 \\
1600 & 650.50 & 648.84 & 647.37 & 649.52 & 649.06 & 1.32 \\
1800 & 681.12 & 679.38 & 677.75 & 680.13 & 679.60 & 1.42 \\
2000 & 709.29 & 707.42 & 705.68 & 708.29 & 707.67 & 1.53 \\
\hline \hline
\end{tabular}

The same excellent consistency is exhibited in the heat capacities, Table 26, as well as for the enthalpy function, Table 27.

\section{Comparison with literature}

(E)-but-2-en-1-ol has reported G2 and G3 entropies of $320 \mathrm{~J} \mathrm{~K}^{-1} \mathrm{~mol}^{-1}$ and of $324 \mathrm{~J} \mathrm{~K}^{-1}$ $\mathrm{mol}^{-1}$ at both CBS-QB3 and G4. These do not match the results obtained here even if allowance is made for 2 optical isomers. Isochoric heat capacities, $C_{v}^{\ominus}$, of 84.8 from G2 and G3 and 90.6 $\mathrm{J} \mathrm{K}^{-1} \mathrm{~mol}^{-1}$ from CBS-QB3 and G4 have been computed. An experimental value of $91.5 \pm 1.8 \mathrm{~J} \mathrm{~K}^{-1} \mathrm{~mol}^{-1}$ is quoted as well a Yaws Handbook ${ }^{75}$ value of $C_{p}^{\ominus}=100 \mathrm{~J} \mathrm{~K}^{-1}$ $\mathrm{mol}^{-1}$. These do agree quite well with our purely vibrational treatment of $C_{p}^{\ominus}=99.5 \pm 5.6$ 
Table 26: Crotyl alcohol: isobaric heat capacity / $\mathrm{J} \mathrm{K}^{-1} \mathrm{~mol}^{-1}$

\begin{tabular}{ccccccc}
\hline$T / \mathrm{K}$ & B3LYP & M06-2X & $\omega$ B97X-D & B2PLYP & $\left\langle C_{p}^{\ominus}\right\rangle$ & $\sigma$ \\
\hline 298.15 & 111.79 & 110.96 & 109.96 & 111.41 & 111.03 & 0.79 \\
300 & 112.15 & 111.33 & 110.33 & 111.78 & 111.40 & 0.79 \\
400 & 131.56 & 131.02 & 130.02 & 131.26 & 130.97 & 0.67 \\
500 & 150.10 & 149.57 & 148.62 & 149.77 & 149.52 & 0.64 \\
600 & 166.76 & 166.17 & 165.28 & 166.39 & 166.15 & 0.63 \\
700 & 181.46 & 180.81 & 179.95 & 181.03 & 180.81 & 0.64 \\
800 & 194.39 & 193.72 & 192.85 & 193.92 & 193.72 & 0.64 \\
900 & 205.78 & 205.15 & 204.21 & 205.31 & 205.11 & 0.66 \\
1000 & 215.84 & 215.28 & 214.22 & 215.37 & 215.18 & 0.68 \\
1100 & 224.71 & 224.25 & 223.04 & 224.28 & 224.07 & 0.72 \\
1200 & 232.54 & 232.17 & 230.81 & 232.16 & 231.92 & 0.76 \\
1300 & 239.46 & 239.15 & 237.67 & 239.15 & 238.86 & 0.81 \\
1400 & 245.59 & 245.28 & 243.72 & 245.33 & 244.98 & 0.85 \\
1500 & 251.02 & 250.66 & 249.08 & 250.83 & 250.40 & 0.89 \\
1600 & 255.85 & 255.36 & 253.84 & 255.70 & 255.19 & 0.92 \\
1800 & 264.00 & 263.07 & 261.87 & 263.89 & 263.21 & 0.98 \\
2000 & 270.52 & 268.97 & 268.33 & 270.38 & 269.55 & 1.07 \\
\hline \hline
\end{tabular}

Table 27: Crotyl alcohol: enthalpy function / $\mathrm{J} \mathrm{K}^{-1} \mathrm{~mol}^{-1}$

\begin{tabular}{ccccccc}
\hline$T / \mathrm{K}$ & B3LYP & M06-2X & $\omega$ B97X-D & B2PLYP & $\left\langle\left(H_{T}^{\ominus}-H_{0}^{\ominus}\right)\right\rangle$ & $\sigma$ \\
\hline 298.15 & 22.06 & 21.81 & 21.54 & 21.96 & 21.84 & 0.23 \\
300 & 22.27 & 22.01 & 21.75 & 22.16 & 22.05 & 0.23 \\
400 & 34.46 & 34.14 & 33.77 & 34.31 & 34.17 & 0.30 \\
500 & 48.55 & 48.18 & 47.71 & 48.38 & 48.21 & 0.36 \\
600 & 64.41 & 63.98 & 63.42 & 64.20 & 64.00 & 0.43 \\
700 & 81.83 & 81.34 & 80.70 & 81.59 & 81.37 & 0.49 \\
800 & 100.64 & 100.08 & 99.35 & 100.34 & 100.10 & 0.55 \\
900 & 120.66 & 120.03 & 119.21 & 120.32 & 120.06 & 0.62 \\
1000 & 141.75 & 141.06 & 140.14 & 141.36 & 141.08 & 0.69 \\
1100 & 163.78 & 163.05 & 162.01 & 163.35 & 163.05 & 0.75 \\
1200 & 186.65 & 185.87 & 184.71 & 186.17 & 185.85 & 0.83 \\
1300 & 210.25 & 209.44 & 208.14 & 209.75 & 209.40 & 0.90 \\
1400 & 234.51 & 233.67 & 232.21 & 233.97 & 233.59 & 0.98 \\
1500 & 259.34 & 258.47 & 256.85 & 258.78 & 258.36 & 1.07 \\
1600 & 284.69 & 283.77 & 282.00 & 284.11 & 283.64 & 1.16 \\
1800 & 336.70 & 335.65 & 333.60 & 336.10 & 335.51 & 1.35 \\
2000 & 390.17 & 388.87 & 386.63 & 389.54 & 388.80 & 1.54 \\
\hline \hline
\end{tabular}


$\mathrm{J} \mathrm{K}^{-1} \mathrm{~mol}^{-1}$.

\section{Case study VI: $\mathrm{H}_{2} \mathrm{C}(\mathrm{OH}) \mathrm{CH}=\mathrm{CHCH}_{2} \mathrm{OH}$}

Finally, we consider a but-2-en-1,4-diol and specifically the E-conformer in the $C_{i}$ molecular point group which also features in the Ghahremanpour et al. large-scale study. ${ }^{74}$ The skew/skew' conformer with $\angle \mathrm{CCCO}$ of $-122^{\circ} /+122^{\circ}$ is the ground state at CBS-QB3 but a skew/syn $\left(122^{\circ} / 7^{\circ}\right)$ is very close at +1.1 with a $C_{2 h}$ conformer at +2.9 and a $C_{2}$ at $7.1 \mathrm{~kJ}$ $\mathrm{mol}^{-1}$.

\section{Frequencies}

The 36 vibrational modes are equally comprised of $a_{g}$ and $a_{u}$ symmetries; anharmonicities returned by M06-2X appear to diverge strongly from those of the other three functionals, for example, \#16, \#17 and \#33, Table 28. Both MN15 and BMK are better behaved in this regard and match the majority closely.

\section{Hindered rotors}

This symmetric system has four single rotatable bonds but in reality only two independent rotors with symmetric and asymmetric components. Thess should be treated therefore as coupled rotors with a $2 \mathrm{D}$ application ${ }^{14}$ but here the focus is on relative uncertainties not absolute ones and so modes \#17, \#18 \#33 and \#36 are replaced by 1D-hindered rotors.

The scans clearly show that although the skew/skew' conformer is the ground state at B3LYP and B2PLYP both BMK and $\omega$ B97X-D are agreed on the skew/syn conformer being the ground state, Fig. 6a. By way of contrast the $\mathrm{CCOH}$ scans, Fig. 6b, are essentially superposable. 
Table 28: (E)-but-2-en-1,4-diol: frequencies and anharmonicities / $\mathrm{cm}^{-1}$

\begin{tabular}{|c|c|c|c|c|c|c|c|c|c|c|}
\hline & \multicolumn{2}{|c|}{ B3LYP } & \multicolumn{2}{|c|}{ BMK } & \multicolumn{2}{|c|}{$\omega \mathrm{B} 97 \mathrm{XD}$} & \multicolumn{2}{|c|}{ B2PLYP } & \multicolumn{2}{|c|}{ Means } \\
\hline$\#$ & $\bar{\nu}$ & $x_{i i}$ & $\bar{\nu}$ & $x_{i i}$ & $\bar{\nu}$ & $x_{i i}$ & $\bar{\nu}$ & $x_{i i}$ & $\langle\bar{\nu}\rangle$ & $\sigma$ \\
\hline 1 & 3805.97 & -43.05 & 3918.07 & -47.69 & 3897.07 & -45.86 & 3829.45 & -42.94 & 362.64 & 3.45 \\
\hline 2 & 3120.77 & -29.53 & 3122.81 & -31.14 & 3150.26 & -40.96 & 3151.59 & -29.15 & 3136.36 & 16.85 \\
\hline 3 & 3056.06 & -26.71 & 3069.83 & -31.87 & 3092.46 & -38.27 & 3094.82 & -25.35 & 3078.29 & 18.62 \\
\hline 4 & 2996.11 & -26.95 & 3003.48 & -30.87 & 3019.17 & -35.02 & 3027.76 & -25.50 & 3011.63 & 14.43 \\
\hline 5 & 1723.27 & -5.90 & 1727.32 & -7.95 & 1761.29 & -7.74 & 1723.21 & -5.93 & 1733.77 & 18.44 \\
\hline 6 & 1504.86 & -3.12 & 1528.82 & -1.16 & 1512.95 & -2.14 & 1518.79 & -2.42 & 1516.36 & 10.09 \\
\hline 7 & 1413.55 & -3.96 & 1429.99 & -4.38 & 1427.82 & -4.02 & 1424.05 & -3.81 & 1423.85 & 7.30 \\
\hline 8 & 1353.46 & -4.15 & 1371.96 & -4.94 & 1366.29 & -4.25 & 1362.06 & -4.08 & 1363.44 & 7.79 \\
\hline 9 & 1322.82 & -1.54 & 1328.52 & -0.53 & 1331.30 & -1.01 & 1325.31 & -1.53 & 1326.99 & 3.71 \\
\hline 10 & 1221.52 & -1.32 & 1232.33 & -1.15 & 1233.50 & -1.38 & 1231.15 & -1.31 & 1229.62 & 5.49 \\
\hline 11 & 1129.70 & -1.23 & 1143.03 & -1.13 & 1142.24 & -1.13 & 1139.58 & -1.22 & 1138.64 & 6.14 \\
\hline 12 & 1035.42 & -4.10 & 1087.06 & -3.32 & 1084.43 & -3.95 & 1048.83 & -4.17 & 1063.93 & 25.79 \\
\hline 13 & 952.93 & -0.39 & 5.87 & -0.59 & 967.02 & -0.40 & 3.78 & -0.38 & 959.90 & 7.58 \\
\hline 14 & 798.42 & -0.19 & 803.82 & -0.20 & 807.72 & -0.17 & 801.04 & -0.11 & 802.75 & 3.98 \\
\hline 15 & 470.08 & -0.66 & 473.10 & -0.72 & 477.53 & -0.84 & 471.68 & -0.62 & 473.10 & 3.20 \\
\hline 16 & 369.12 & -1.82 & & & 17 & -4.23 & 53 & -1.94 & & 4.01 \\
\hline 17 & 330.46 & -7.31 & 340.00 & -5.73 & 333.94 & -22.62 & 333.82 & -5.76 & 334.55 & 3.97 \\
\hline 18 & 138.08 & -0.46 & 137.95 & -0.38 & 133.63 & -0.37 & 136.99 & 0.14 & 136.66 & 2.08 \\
\hline 19 & 3806.14 & -43.04 & 3918.23 & -47.69 & 7.21 & -45.86 & 3829.60 & -42.93 & 3862.79 & 53.45 \\
\hline 20 & 3126.55 & -28.60 & 3127.05 & -30.49 & 3152.33 & -40.22 & 3156.18 & -28.21 & 3140.53 & 15.93 \\
\hline 21 & 3055.70 & -26.90 & 3069.59 & -32.12 & 3092.22 & -38.35 & 3094.37 & -25.43 & 3077.97 & 18.61 \\
\hline 22 & 2995.42 & -26.91 & 3002.91 & -30.94 & 3018.68 & -34.98 & 3027.18 & -25.48 & 3011.05 & 14.48 \\
\hline 23 & 1504.83 & -2.77 & 1528.86 & -1.12 & 1512.86 & -1.85 & 1518.67 & -2.10 & 1516.30 & 10.11 \\
\hline 24 & 1414.75 & -4.22 & 1431.57 & -5.14 & 1430.16 & -4.46 & 1425.21 & -4.08 & 1425.42 & 7.62 \\
\hline 25 & 1378.08 & -2.72 & 1394.68 & -3.14 & 1391.38 & -2.88 & 1386.91 & -2.75 & 1387.76 & 7.20 \\
\hline 26 & 1305.87 & -1.61 & 1309.54 & -1.06 & 1310.89 & -1.43 & 1311.68 & -1.62 & 1309.49 & 2.57 \\
\hline 27 & 1186.99 & -1.18 & 1201.28 & -1.27 & 1200.73 & -1.29 & 1194.54 & -1.18 & 1195.89 & 6.67 \\
\hline 28 & 1088.69 & -2.79 & 1110.87 & -2.15 & 1115.69 & -2.47 & 1105.27 & -2.70 & 1105.13 & 11.76 \\
\hline 29 & 1016.56 & -1.58 & 1048.59 & -1.37 & 1048.56 & -1.73 & 1025.98 & -2.20 & 1034.92 & 16.23 \\
\hline 30 & 1012.55 & -1.41 & 1029.30 & -4.14 & 1024.22 & -2.83 & 1018.51 & -2.58 & 1021.14 & 7.23 \\
\hline 31 & 962.10 & -0.34 & 971.30 & -0.16 & 970.36 & -0.13 & 968.71 & -0.31 & 968.12 & 4.15 \\
\hline 32 & 552.05 & -0.01 & 563.09 & 0.02 & 562.34 & 0.08 & 555.05 & 0.01 & 558.13 & 5.44 \\
\hline 33 & 350.97 & -9.84 & 361.79 & -10.63 & 355.68 & -26.34 & 355.16 & -9.38 & 355.90 & 4.46 \\
\hline 34 & 263.69 & -1.06 & 267.48 & -1.06 & 269.26 & -4.73 & 264.85 & -0.71 & 266.32 & 2.52 \\
\hline 35 & 124.76 & -0.21 & 126.97 & 0.14 & 126.29 & 0.18 & 125.07 & -0.15 & 125.77 & 1.04 \\
\hline 36 & 63.27 & -1.32 & 64.50 & -0.12 & 59.71 & 0.68 & 63.23 & -1.17 & 62.68 & 2.06 \\
\hline
\end{tabular}




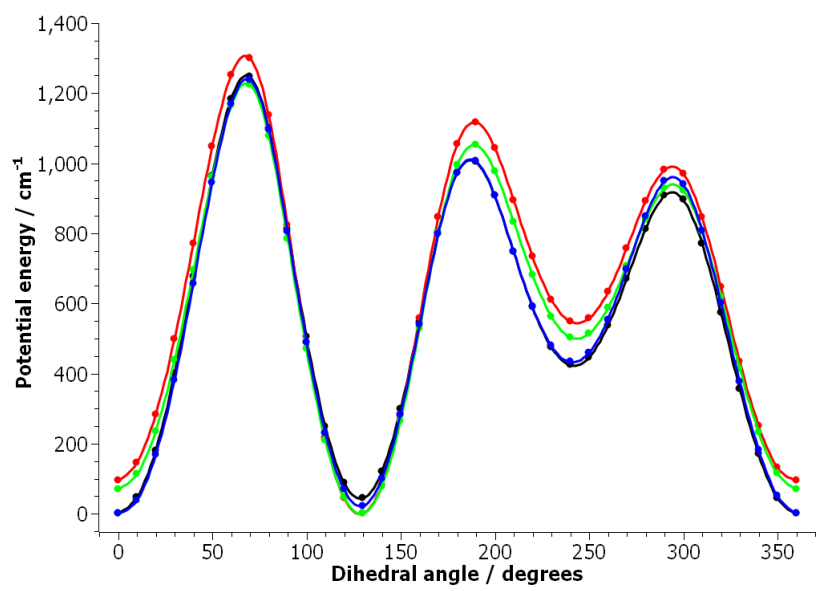

(a) Scans of CCCO

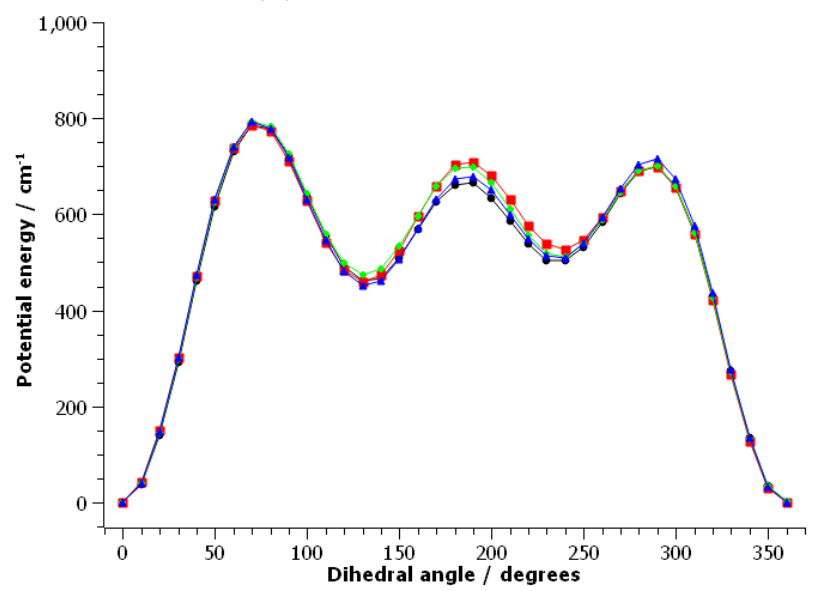

(b) Scans of $\mathrm{CCOH}$

Figure 6: B3LYP —, BMK —, $\omega$ B97XD —, B2PLYP - 


\section{Entropy and heat capacity}

Replacing four vibrational modes by hindered rotors increases the entropy considerably from $354.34 \rightarrow 383.97 \mathrm{~J} \mathrm{~K}^{-1} \mathrm{~mol}^{-1}$ at $298.15 \mathrm{~K}$; there is also a concomitant decrease in the uncertainty from $\pm 2.88 \rightarrow \pm 0.57 \mathrm{~J} \mathrm{~K}^{-1} \mathrm{~mol}^{-1}$. Although at room temperature there is good agreement between the different functionals M06-2X is progressively out of step and is in substantial disagreement by $2,000 \mathrm{~K}$. Much the same conclusion can be applied to $C_{p}^{\ominus}$; good agreement at $300 \mathrm{~K}, \mathrm{M} 06-2 \mathrm{X}$ some way out of line at the highest temperature. It is replaced by the BMK functional which improves agreement at the highest temperature, viz. $S^{\ominus}=782.94$ and $C_{p}^{\ominus}=289.25$; these are to be compared with $\left\langle S^{\ominus}\right\rangle=785.26 \pm 1.09$ and $\left\langle C_{p}^{\ominus}\right\rangle=287.70 \pm 1.90$, all in $\mathrm{J} \mathrm{K}^{-1} \mathrm{~mol}^{-1}$ - much the same improvement is also seen with MN15.

Table 29: (E)-but-2-en-1,4-diol: entropy / $\mathrm{J} \mathrm{K}^{-1} \mathrm{~mol}^{-1}$

\begin{tabular}{ccccccc}
\hline$T / \mathrm{K}$ & B3LYP & BMK & $\omega$ B97X-D & B2PLYP & $\left\langle S^{\ominus}\right\rangle$ & $\sigma$ \\
\hline 298.15 & 384.71 & 381.65 & 383.60 & 383.97 & 383.48 & 1.31 \\
300 & 385.54 & 382.48 & 384.43 & 384.79 & 384.31 & 1.30 \\
400 & 426.54 & 423.61 & 425.41 & 425.67 & 425.31 & 1.23 \\
500 & 462.56 & 459.69 & 461.44 & 461.60 & 461.32 & 1.20 \\
600 & 495.18 & 492.30 & 494.12 & 494.13 & 493.93 & 1.20 \\
700 & 525.15 & 522.23 & 524.19 & 524.00 & 523.89 & 1.22 \\
800 & 552.92 & 549.95 & 552.11 & 551.68 & 551.67 & 1.25 \\
900 & 578.82 & 575.80 & 578.16 & 577.49 & 577.57 & 1.30 \\
1000 & 603.10 & 600.02 & 602.57 & 601.67 & 601.84 & 1.35 \\
1100 & 625.94 & 622.80 & 625.52 & 624.42 & 624.67 & 1.40 \\
1200 & 647.51 & 644.32 & 647.16 & 645.90 & 646.22 & 1.44 \\
1300 & 667.93 & 664.70 & 667.62 & 666.24 & 666.62 & 1.48 \\
1400 & 687.31 & 684.04 & 687.00 & 685.55 & 685.98 & 1.50 \\
1500 & 705.75 & 702.45 & 705.41 & 703.91 & 704.38 & 1.51 \\
1600 & 723.32 & 720.00 & 722.92 & 721.41 & 721.91 & 1.52 \\
1800 & 756.15 & 752.81 & 755.53 & 754.11 & 754.65 & 1.49 \\
2000 & 786.30 & 782.94 & 785.36 & 784.12 & 784.68 & 1.46 \\
\hline \hline
\end{tabular}


Table 30: (E)-but-2-en-1,4-diol:: isobaric heat capacity / $\mathrm{J} \mathrm{K}^{-1} \mathrm{~mol}^{-1}$

\begin{tabular}{ccccccc}
\hline$T / \mathrm{K}$ & B3LYP & BMK & $\omega$ B97X-D & B2PLYP & $\left\langle C_{p}^{\ominus}\right\rangle$ & $\sigma$ \\
\hline 298.15 & 133.06 & 133.48 & 132.99 & 132.60 & 133.03 & 0.36 \\
300 & 133.42 & 133.84 & 133.35 & 132.96 & 133.39 & 0.36 \\
400 & 152.49 & 152.89 & 152.47 & 152.10 & 152.49 & 0.32 \\
500 & 170.79 & 170.88 & 170.92 & 170.32 & 170.73 & 0.28 \\
600 & 187.23 & 187.07 & 187.72 & 186.66 & 187.17 & 0.44 \\
700 & 201.67 & 201.33 & 202.55 & 200.99 & 201.64 & 0.67 \\
800 & 214.33 & 213.87 & 215.51 & 213.56 & 214.32 & 0.86 \\
900 & 225.47 & 224.94 & 226.78 & 224.62 & 225.45 & 0.95 \\
1000 & 235.30 & 234.74 & 236.55 & 234.40 & 235.25 & 0.94 \\
1100 & 243.99 & 243.42 & 245.02 & 243.04 & 243.87 & 0.86 \\
1200 & 251.68 & 251.12 & 252.36 & 250.68 & 251.46 & 0.73 \\
1300 & 258.48 & 257.97 & 258.74 & 257.45 & 258.16 & 0.57 \\
1400 & 264.51 & 264.06 & 264.30 & 263.45 & 264.08 & 0.46 \\
1500 & 269.87 & 269.49 & 269.14 & 268.78 & 269.32 & 0.47 \\
1600 & 274.65 & 274.35 & 273.37 & 273.53 & 273.98 & 0.62 \\
1800 & 282.78 & 282.59 & 280.31 & 281.56 & 281.81 & 1.13 \\
2000 & 289.39 & 289.25 & 285.64 & 288.06 & 288.09 & 1.74 \\
\hline \hline
\end{tabular}

\section{Enthalpy function}

This follows the previous pattern of good agreement for all four DFs at $300 \mathrm{~K}$ but then M06-2X departs considerably at the highest temperature, viz. 27.23 at $300 \mathrm{~K}$ and 402.22 at 2,000 K. BMK reports good agreement both at room temperature, 26.50 vs $\left\langle\left(H_{T}-H_{0}\right)\right\rangle=$ $26.37 \pm 0.17$, and at high temperature 427.35 vs $\left\langle\left(H_{T}-H_{0}\right)\right\rangle=427.04 \pm 0.96 \mathrm{~kJ} \mathrm{~mol}^{-1}$, Table 31 .

\section{Comparison with literature}

G2 and G3 values ${ }^{74}$ of 348 and a $356 \mathrm{~J} \mathrm{~K}^{-1} \mathrm{~mol}^{-1}$ for $\mathrm{G} 4$ are very different to the result shown here; although a rotatable bonds correction increases the G2-G4 values by $+17 \mathrm{~J}$ $\mathrm{K}^{-1} \mathrm{~mol}^{-1}$ this still falls some way short. Excellent agreement is however obtained with the $S^{\ominus}=383 \pm 7 \mathrm{~J} \mathrm{~K}^{-1} \mathrm{~mol}^{-1}$ of the Yaws Handbook. ${ }^{75}$

G2-G4 values ${ }^{74}$ for the isobaric heat capacity of 108,108 and $115 \mathrm{~J} \mathrm{~K}^{-1} \mathrm{~mol}^{-1}$ at $298.15 \mathrm{~K}$ are in reasonably agreement with our purely vibrational treatment of $115.8 \pm 1.5 \mathrm{~J} \mathrm{~K}^{-1} \mathrm{~mol}^{-1}$. 
Table 31: (E)-but-2-en-1,4-diol: enthalpy function / $\mathrm{kJ} \mathrm{mol}^{-1}$

\begin{tabular}{ccccccc}
\hline$T / \mathrm{K}$ & B3LYP & BMK & $\omega$ B97X-D & B2PLYP & $\left\langle\left(H_{T}^{\ominus}-H_{0}^{\ominus}\right)\right\rangle$ & $\sigma$ \\
\hline 298.15 & 26.47 & 26.50 & 26.47 & 26.18 & 26.41 & 0.15 \\
300 & 26.72 & 26.75 & 26.71 & 26.43 & 26.65 & 0.15 \\
400 & 41.01 & 41.09 & 41.01 & 40.68 & 40.95 & 0.18 \\
500 & 57.19 & 57.29 & 57.18 & 56.82 & 57.12 & 0.21 \\
600 & 75.11 & 75.20 & 75.13 & 74.68 & 75.03 & 0.24 \\
700 & 94.56 & 94.64 & 94.66 & 94.08 & 94.49 & 0.27 \\
800 & 115.38 & 115.41 & 115.57 & 114.82 & 115.30 & 0.33 \\
900 & 137.38 & 137.36 & 137.70 & 136.73 & 137.29 & 0.41 \\
1000 & 160.42 & 160.35 & 160.88 & 159.69 & 160.34 & 0.49 \\
1100 & 184.39 & 184.26 & 184.96 & 183.57 & 184.30 & 0.57 \\
1200 & 209.18 & 209.00 & 209.84 & 208.26 & 209.07 & 0.65 \\
1300 & 234.69 & 234.45 & 235.40 & 233.67 & 234.55 & 0.71 \\
1400 & 260.85 & 260.56 & 261.55 & 259.72 & 260.67 & 0.76 \\
1500 & 287.57 & 287.24 & 288.23 & 286.34 & 287.35 & 0.79 \\
1600 & 314.80 & 314.43 & 315.36 & 313.45 & 314.51 & 0.80 \\
1800 & 370.56 & 370.15 & 370.75 & 368.99 & 370.11 & 0.79 \\
2000 & 427.80 & 427.35 & 427.36 & 425.97 & 427.12 & 0.79 \\
\hline \hline
\end{tabular}

\section{Recommendations}

For convenience a summary of the results is presented in Table 32 together with uncertainties, $u= \pm 2 \sigma$.

Table 32: Recommended values at $298.15 \mathrm{~K} / \mathrm{J}, \mathrm{kJ}, \mathrm{K}$, mol

\begin{tabular}{lccc}
\hline Species name & $S^{\ominus}$ & $C_{p}^{\ominus}$ & $\left(H_{T}^{\ominus}-H_{0}^{\ominus}\right)$ \\
\hline trans-glyoxal & $271.62 \pm 0.32$ & $59.62 \pm 0.21$ & $13.58 \pm 0.04$ \\
formyloxy oxomethyl & $309.89 \pm 1.22$ & $73.04 \pm 1.32$ & $16.30 \pm 0.28$ \\
methoxy oxomethoxy & $311.15 \pm 3.24$ & $74.54 \pm 2.20$ & $16.32 \pm 0.72$ \\
n-propyldioxy & $355.82 \pm 1.58$ & $95.66 \pm 1.44$ & $20.35 \pm 0.56$ \\
(E)-crotyl alcohol & $345.30 \pm 0.60$ & $111.03 \pm 1.58$ & $21.84 \pm 0.46$ \\
(E)-but-2-en-1,4-diol & $383.48 \pm 2.61$ & $133.03 \pm 0.72$ & $26.41 \pm 0.30$ \\
\hline \hline
\end{tabular}

\section{Conclusions}

The use of a number of density functionals to calculate the properties of molecules means that an estimate, however crude, of the uncertainty associated with derived quantities such 
as those of primary concern here namely, entropy, heat capacity and enthalpy function can be obtained. In those few cases that have been explored in this work it is shown that an earlier estimate is unduly pessimistic.

These results provide useful targets against which different functionals can be tested but only for those species whose derived values show some sensitivity to either functional, basis set, or indeed treatment of vibrational modes as harmonic or anharmonic oscillators, or hindered rotors.

Those species which lack this sensitivity renders them of marginal value for inclusion in databases - thus the presence of, for example, glyoxal or ethanal in a thermochemistry database which has been built to validate new methods or to evaluate machine-learning methods, serves little purpose since the outcomes are so insensitive.

Our case-by-case study indicates that the choice of an appropriate density functional — wavefunction theory is eschewed because of prohibitive cost — will be key to achieving reasonably precise results. In particular although it is often remarked that vibrational anharmonicities are not worthwhile, since scaling can be done, it is recommended here since it can show up deficiencies.

\section{ORCID}

John M. Simmie: 0000-0003-0714-7956

\section{Acknowledgement}

The Irish Centre for High-End Computing, ICHEC, is thanked for the provision of computational resources (projects: nuig02, ngche071b). 


\section{References}

(1) De Bortoli, A.L.; Andreis, G.S.L.; Pereira, F.N. Modeling and Simulation of Reactive Flows, Elsevier, New York, 2015.

(2) Peng, Z.; Jimenez, J. L., Radical Chemistry in Oxidation Flow Reactors for Atmospheric Chemistry Research. Chem. Soc. Revs. 2020, 49, 2570-2616.

(3) Simmie, J. M., Detailed Chemical Kinetic Models for the Combustion of Hydrocarbon Fuels. Prog. Energy Combust. Sci. 2003, 29, 599-634.

(4) Goldsmith, C. F.; Magoon, G.R.; Green, W.H. Database of Small Molecule Thermochemistry for Combustion. J. Phys. Chem. A 2012, 116, 9033-9057.

(5) Červinka, C.; Fulem, M.; Štejfa, V.; Růžička, K. Analysis of Uncertainty in the Calculation of Ideal-Gas Thermodynamic Properties Using the One-Dimensional Hindered Rotor (1-DHR) Model. J. Chem. Eng. Data, 2017, 62, 445-455.

(6) Červinka, C.; Fulem, M.; Růžička, K. Evaluation of Uncertainty of Ideal-Gas Entropy and Heat Capacity Calculations by Density Functional Theory (DFT) for Molecules Containing Symmetrical Internal Rotors. J. Chem. Eng. Data 2013, 58, 1382-1390.

(7) Simmie, J.M.; Somers, K.P. Benchmarking Compound Methods (CBS-QB3, CBSAPNO, G3, G4, W1BD) against the Active Thermochemical Tables: A Litmus Test for Cost-Effective Molecular Formation Enthalpies. J. Phys. Chem. A 2015, 119, 72357246 .

(8) Somers, K.P.; Simmie, J.M. Benchmarking Compound Methods (CBS-QB3, CBSAPNO, G3, G4, W1BD) against the Active Thermochemical Tables: Formation Enthalpies of Radicals. J. Phys. Chem. A, 2015, 119, 8922-8933.

(9) Simmie, J.M. A Database of Formation Enthalpies of Nitrogen Species by Compound Methods (CBS-QB3, Cbs-APNO, G3, G4). J. Phys. Chem. A, 2015, 119, 10511-10526. 
(10) Simmie, J. M.; Sheahan, J. N., Validation of a Database of Formation Enthalpies and of Mid-Level Model Chemistries. J. Phys. Chem. A, 2016, 120, 7370-7384.

(11) Cooksy, A. Physical Chemistry: Thermodynamics, Statistical Mechanics \& Kinetics, Pearson, 2014, ISBN-13: 978-0-321-81415-9

(12) Ocola, E. J.; Laane, J. Ring-puckering potential energy functions for cyclobutane and related molecules based on refined kinetic energy expansions and theoretical calculations. Chem. Phys. 2020, 532, 110647

(13) Császár, A. G.; Aarset, K. Anharmonic force field, vibrational energies, and barrier to inversion of $\mathrm{SiH}_{3}^{-}$, J. Chem. Phys. 2000, 112, 4053-4063.

(14) Ferro-Costas, D.; Cordeiro, M.; Truhlar, D. G.; Fernandez-Ramos, A., Q2DTor: A Program to Treat Torsional Anharmonicity through Coupled Pair Torsions in Flexible Molecules. Comput. Phys. Comms. 2018, 232, 190-205.

(15) Becke, A. D. J. Cem. Phys., Density-Functional Thermochemistry.3. The Role of Exact Exchange. 1993, 98, 5648-5652

(16) Stephens, P.J.; Devlin, F.J.; Chabalowski, C.F.; Frisch, M.J. Ab-initio calculation of vibrational absorption and circular-dichroism spectra using density-functional forcefields. J. Phys. Chem., 1994, 98, 11623-11627

(17) Boese, A. D.; Martin, J. M. L. Development of density functionals for thermochemical kinetics. J. Chem. Phys. 2004, 121, 3405-3416.

(18) Zhao, Y.; Truhlar, D. G., The M06 Suite of Density Functionals for Main Group Thermochemistry, Thermochemical Kinetics, Noncovalent Interactions, Excited States, and Transition Elements: Two New Functionals and Systematic Testing of Four M06-Class Functionals and 12 Other Functionals. Theor. Chem. Accts 2008, 120, 215-241. 
(19) Chai, J.D.; Head-Gordon, M. Long-range corrected hybrid density functionals with damped atom-atom dispersion corrections. Phys. Chem. Chem. Phys. 2008, 10, 66156620.

(20) Peverati, R.; Truhlar, D. G. An improved and broadly accurate local approximation to the exchange-correlation density functional: The MN12-L functional for electronic structure calculations in chemistry and physics. Phys. Chem. Chem. Phys. 2012, 14, $13171-13174$.

(21) Yu, H.S.; He, X.; Li, S. L.; Truhlar, D. G. MN15: A Kohn-Sham Global-Hybrid Exchange-Correlation Density Functional with Broad Accuracy for Multi-Reference and Single-Reference Systems and Noncovalent Interactions, Chemical Science 2016, 7, 5032-5051.

(22) Brémond, E.; Ciofini, I.; Sancho-García, J.C.; Adamo, C. Nonempirical Double-Hybrid Functionals: An Effective Tool for Chemists. Accts. Chem. Res. 2016, 49, 1503-1513.

(23) Grimme, S., Semiempirical Hybrid Density Functional with Perturbative Second-Order Correlation. J. Chem. Phys. 2006, 124, 034108.

(24) Morgante, P.; Peverati, R., The Devil in the Details: A Tutorial Review on Some Undervalued Aspects of Density Functional Theory Calculations. Int . J. Quantum Chem. 2020, 120:e26332.

(25) Gaussian 16, Revision C.01, Frisch, M. J.; Trucks, G. W.; Schlegel, H. B.; Scuseria, G. E.; Robb, M. A.; Cheeseman, J. R.; Scalmani, G.; Barone, V.; Petersson, G. A.; Nakatsuji, H.; et al. Gaussian, Inc., Wallingford CT, 2016.

(26) Chemcraft v1.8 htpps://www . chemcraftprog.com

(27) Barker, J. R.; Nguyen, T. L.; Stanton, J. F.; Aieta, C.; Ceotto, M.; Gabas, F.; Kumar, T. J. D.; Li, C. G. L.; Lohr, L. L.; Maranzana, A., Ortiz, N. F.; Preses, J.M.; Simmie, 
J. M.; Sonk, J. A.; Stimac, P. J. Multiwell-2017 Software Suite, Ann Arbor, Michigan, USA, 2017. http://clasp-research.engin.umich.edu/multiwell/

(28) Tahchieva, D.N.; Bakowies, D.; Ramakrishnan, R.; von Lilienfeld, O. A. Torsional Potentials of Glyoxal, Oxalyl Halides and Their Thiocarbonyl Derivatives: Challenges for Popular Density Functional Approximations. J. Chem. Theo. Comput., 2018, 14, 4806-4817.

(29) Saghafi, H.; Vahedpour, M. Atmospheric reactions of glyoxal with NO2 and NH2 radicals: Hydrogen abstraction mechanism and natural bond orbital analysis. 2019, 44, $187-209$.

(30) Lu, X-W.; Jiang, L-X. ; Liu, J.; Yang, Y.; Liu, Q-Y.; Ren, Y.; Li, X.; He, S-G. Sensitive Detection of Gas-Phase Glyoxal by Electron Attachment Reaction Ionization Mass Spectrometry. Anal. Chem. 2019, 91, 12688-12695.

(31) da Silva, G., Hydroxyl Radical Regeneration in the Photochemical Oxidation of Glyoxal: Kinetics and Mechanism of the $\mathrm{HC}(\mathrm{O}) \mathrm{CO}+\mathrm{O}_{2}$ Reaction. Phys. Chem. Chem. Phys. 2010, 12, 6698-6705.

(32) Jacobsen, R. L.; Johnson, R. D.; Irikura, K. K.; Kacker, R. N., Anharmonic Vibrational Frequency Calculations Are Not Worthwhile for Small Basis Sets. J. Chem. Theo. Comput. 2013, 9, 951-954.

(33) Kesharwani, M.K.; Brauer, B.; Martin, J.M.L. Frequency and Zero-Point Vibrational Energy Scale Factors for Double-Hybrid Density Functionals (and Other Selected Methods): Can Anharmonic Force Fields Be Avoided? J. Phys. Chem. A 2015, 119, 17011714 .

(34) Butz, K. W.; Krajnovich, D. J.; Parmenter, C. S. An Experimental Potential-Energy Surface for Internal-Rotation in Glyoxal. J. Chem. Phys. 1990, 93, 1557-1567. 
(35) Gao, Y.; He, T.; Li, X.; You, X. Effect of hindered internal rotation treatments on predicting the thermodynamic properties of alkanes. PCCP, 2019, 21, 1928-1936.

(36) Zheng, J.; Truhlar, D. G. Quantum Thermochemistry: Multistructural Method with Torsional Anharmonicity Based on a Coupled Torsional Potential. J. Chem. Theo. Comput., 2013, 9, 1356-1367.

(37) Goos, E.; Burcat, A.; Ruscic, B. Extended Third Millennium Ideal Gas and Condensed Phase Thermochemical Database for Combustion with Updates from Active Thermochemical Tables. http://garfield.chem.elte.hu/Burcat/burcat.html; 05 September 2020.

(38) Barone, V. Vibrational zero-point energies and thermodynamic functions beyond the harmonic approximation. J. Chem. Phys. 2004, 120, 3059-3065.

(39) Ayala, P.Y.; Schlegel, H.B. Identification and treatment of internal rotation in normal mode vibrational analysis. J. Chem. Phys. 1998, 108, 2314-2325.

(40) Thermodynamics Research Center, Selected Values of Properties of Chemical Compounds (Texas A \& M University, College Station, Texas, USA).

(41) Chao, J.; Hall, K. R.; Marsh, K. N.; Wilhoit, R. C. Thermodynamic Properties of Key Organic Oxygen Compounds in the Carbon Range C1 to C4. Part 2. Ideal Gas Properties. J. Phys. Chem. Re. Data, 1986, 15, 1369-1436.

(42) Ruscic, B. and Bross, D. H., Active Thermochemical Tables (ATcT) values based on ver. 1.122 of the Thermochemical Network (2016); available at http: //atct.anl.gov/ ThermochemicalData/ accessed 25-May-2017.

(43) Simmie, J.M.; Somers, K.P. Snakes on the Rungs of Jacob's Ladder: Anomalous Vibrational Spectra from Double-Hybrid DFT Methods. J. Phys. Chem. A, 2020, 124, 6899-6902. 
(44) Bühl, M.; DaBell, P.; Manley, D.W.; McCaughan, R.P.; Walton, J.C. Bicarbonate and Alkyl Carbonate Radicals: Structural Integrity and Reactions with Lipid Components. J. Am. Chem. Soc. 2015, 137, 16153-16162

(45) Glaude, P.A; Pitz, W.J.; Thomson, M.J. Chemical kinetic modeling of dimethyl carbonate in an opposed-flow diffusion flame. Proc. Combust. Inst. 2005, 30, 1111-1118.

(46) Atherley, T; de Persis, S.; Chaumeix, N.; Fernandes, Y. ; Bry, A. ; Comandini, A.; Mathieu, O.; Alturaifi, S.; Mulvihill, C.R.; Petersen, E.L. Laminar flame speed and shock-tube multi-species laser absorption measurements of Dimethyl Carbonate oxidation and pyrolysis near 1 atm. Proc. Combust. Inst. 2020 https://doi.org/10.1016/j.proci.2020.06.333

(47) Sun, W.; Yang, B.; Hansen, N.; Westbrook, C.K.; Zhang, F.; Wang, G.; Moshammer, K.; Law, C.K. An experimental and kinetic modeling study on dimethyl carbonate (DMC) pyrolysis and combustion. Combust. Flame, 2016, 164, 224-238.

(48) Wu, X.; Zhou, X.; Hemberger, P.; Bodi, A. Dissociative Photoionization of Dimethyl Carbonate: The More It Is Cut, the Bigger the Fragment Ion. J. Phys. Chem. A, 2017, $121,2748-2759$.

(49) Tundo, P.; Selva, M., The Chemistry of Dimethyl Carbonate. Acc. Chem. Res. 2002, $35,706-716$.

(50) Berasategui, M.; Burgos Paci, M. A.; Argüello, G. A., Properties and Thermal Decomposition of the Hydro-Fluoro-Peroxide $\mathrm{CH}_{3} \mathrm{OC}(\mathrm{O}) \mathrm{OOC}(\mathrm{O})$ F. J. Phys. Chem. A 2014, $118,2167-2175$.

(51) Lee, T. J.; Taylor, P. R., A Diagnostic for Determining the Quality of Single-reference Electron Correlation Methods. Int. J. Quantum Chem. 1989, 36, 199-207. 
(52) Gao, Y.; You, X. On the Prediction of Standard Enthalpy of Formation of C2C4 Oxygenated Species. J. Phys. Chem. A 2019, 123, 11004-11011.

(53) Simmie, J.M.; Würmel, J. An Organised Collection of Theoretical Gas-Phase Geometric, Spectroscopic and Thermochemical Data of Oxygenated Hydrocarbons, $\mathrm{C}_{\mathrm{x}} \mathrm{H}_{\mathrm{y}} \mathrm{O}_{\mathrm{z}}$ $(x=y=1,2 ; z=1 \rightarrow 8)$, of Relevance to Atmospheric, Astrochemical and Combustion Sciences. J. Phys. Chem. Ref. Data 2020

(54) Curtiss, L. A.; Redfern, P. C.; Raghavachari, K., Gaussian-4 Theory. J. Chem. Phys. 2007, 126, 084108 .

(55) Vuckovic, S.; Burke, K. Quantifying and Understanding Errors in Molecular Geometries. J. Phys. Chem. Lett. 2020, 11, 9957-9964.

(56) Y. Zhao and D. G. Truhlar, The M06 suite of density functionals for main group thermochemistry, thermochemical kinetics, noncovalent interactions, excited states, and transition elements: two new functionals and systematic testing of four M06-class functionals and 12 other functionals, Theor. Chem. Acc., 2008, 120, 215-241.

(57) Kanchanakungwankul, S.; Bao, J. L.; Zheng, J.; Alecu, I. M.; Lynch, B. J.; Zhao, .; Truhlar, D. G. Database of Frequency Scale Factors for Electronic Model Chemistries - Version 4. 07-Jan-2018, http://comp.chem.umn.edu/freqscale/190107

(58) Xiaoqing You (Tsinghua Univ.), personal communication, 8th October 2020.

(59) Yang, Z.; Lin, X.; Zhou, J.; Hu, M.; Gai, Y.; Zhao, W.; Bo, I.; Zhang, W., Computational Study on the Mechanism and Kinetics for the Reaction between $\mathrm{HO}_{2}$ and N-Propyl Peroxy Radical. RSC Adv. 2019, 9, 40437-40444.

(60) Xu, Y.; Xi, S.; Wang, F.; Li, X., Theoretical Study on Reactions of Alkylperoxy Radicals. J. Phys. Chem. A 2019, 123, 3949-3958. 
(61) Wang, H.; Bozzelli, J. W., Thermochemical Properties $\left[\Delta_{f} H^{\ominus}(298 \mathrm{~K}), S^{\ominus}(298 \mathrm{~K})\right.$, $\left.C_{p}^{\ominus}(T)\right]$ and Bond Dissociation Energies for C1-C4 Normal Hydroperoxides and Peroxy Radicals. J. Chem. Eng. Data 2016, 61, 1836-1849.

(62) Hoobler, P. R.; Turney, J. M.; Schaefer, H. F., Investigating the Ground-State Rotamers of N-Propylperoxy Radical. J. Chem. Phys. 2016, 145, 174301/1-10.

(63) Welz, O.; Burke, M. P.; Antonov, I. O.; Goldsmith, C. F.; Savee, J. D.; Osborn, D. L.; Taatjes, C. A.; Klippenstein, S. J.; Sheps, L., New Insights into Low-Temperature Oxidation of Propane from Synchrotron Photoionization Mass Spectrometry and MultiScale Informatics Modeling. J. Phys. Chem. A 2015, 119, 7116-7129.

(64) Huynh, L. K.; Carstensen, H.-H.; Dean, A. M., Detailed Modeling of Low-Temperature Propane Oxidation: 1. The Role of the Propyl $+\mathrm{O}_{2}$ Reaction. J. Phys. Chem. A 2010, $114,6594-6607$.

(65) Just, G. M. P.; Rupper, P.; Miller, T. A.; Meerts, W. L., High-Resolution Cavity Ringdown Spectroscopy of the Jet-Cooled Propyl Peroxy Radical $\mathrm{C}_{3} \mathrm{H}_{7} \mathrm{O}_{2}$. Phys. Chem. Chem. Phys. 2010, 12, 4773-4782.

(66) Zalyubovsky, S. J.; Glover, B. G.; Miller, T. A.; Hayes, C.; Merle, J. K.; Hadad, C. M., Observation of the $\tilde{A} \leftarrow \tilde{X}$ Electronic Transition of the $1-\mathrm{C}_{3} \mathrm{H}_{7} \mathrm{O}_{2}$ and $2-\mathrm{C}_{3} \mathrm{H}_{7} \mathrm{O}_{2}$ Radicals Using Cavity Ringdown Spectroscopy. J. Phys. Chem. A 2005, 109, 13081315.

(67) Tarczay, G.; Zalyubovsky, S. J.; Miller, T. A., Conformational Analysis of the 1- and 2-Propyl Peroxy Radicals. Chem. Phys. Lett. 2005, 406, 81-89.

(68) Villano, S. M.; Huynh, L. K.; Carstensen, H.-H.; Dean, A. M., High-Pressure Rate Rules for Alkyl $+\mathrm{O}_{2}$ Reactions. 1. The Dissociation, Concerted Elimination, and Isomerization Channels of the Alkyl Peroxy Radical. J. Phys. Chem. A 2011, 115, 13425-13442. 
(69) Burke, S. M.; Simmie, J. M.; Curran, H. J., Critical Evaluation of Thermochemical Properties of C-1-C-4 Species: Updated Group-Contributions to Estimate Thermochemical Properties. J. Phys. Chem. Ref. Data 2015, 44, 013101.

(70) Mitra, H.; Roy, T. K. Comprehensive Benchmark Results for the Accuracy of Basis Sets for Anharmonic Molecular Vibrations. J. Phys. Chem. A https://dx.doi.org/10.1021/acs.jpca.0c06634

(71) Lee, K.L.K.; McCarthy, M. Bayesian Analysis of Theoretical Rotational Constants from Low- Cost Electronic Structure Methods. J. Phys. Chem. A 2020, 124, 898-910.

(72) Montgomery, J. A.; Frisch, M. J.; Ochterski, J. W.; Petersson, G. A., A Complete Basis Set Model Chemistry. Vii. Use of the Minimum Population Localization Method. J. Chem. Phys. 2000, 112, 6532-6542.

(73) Curtiss, L. A.; Redfern, P. C.; Raghavachari, K., Gn Theory. Wiley Interdisciplinary Reviews-Computational Molecular Science 2011, 1, 810-825.

(74) Ghahremanpour, M.M.; van Maaren, P.J.; Ditz, J.C.; Lindh, R.; van der Spoel, D. Large-scale calculations of gas phase thermochemistry: Enthalpy of formation, standard entropy, and heat capacity. J. Chem. Phys. 2016, 145, 114305.

(75) Yaws, C. L. Yaws Handbook of Thermodynamic Properties for Hydrocarbons and Chemicals; 2009, Knovel: http://www.knovel.com 